\title{
LA MUTANTE LECTURA GEOGRÁFICA DE LAS MONTAÑAS GALLEGAS: DE SU «DIFICULTAD DE ESTUDIO» A «PERIFERIA EN MUY ACUSADA CRISIS»
}

\author{
Rubén C. Lois González \\ Valerià Paül Carril \\ Departamento de Xeografía \\ Universidade de Santiago de Compostela
}

\section{RESUMEN}

Este trabajo asume las montañas de Galicia como una realidad construida. En particular, analiza la aportación que ha realizado la Geografía, como disciplina, y la Ordenación del Territorio, como su vertiente aplicada y política, a dicha construcción discursiva. Se parte de una revisión teórica y metodológica de la bibliografía existente dedicada a las representaciones académicas, sociales, políticas o culturales de las montañas. En el primer apartado analítico se estudia la cartografía y el conocimiento geográfico preacadémico de los últimos siglos, período en el que domina una imagen caótica de las montañas gallegas. A continuación se consideran las décadas de 1970 y 1980, momento clave en el que la Geografía institucionalizada fija la lectura preponderante de las montañas gallegas que llega a fecha de hoy. Finalmente, se explican los desarrollos investigadores y de ordenación del territorio producidos en las últimas décadas: el diagnóstico común insiste en el carácter periférico y marginal de las montañas gallegas, pero los mecanismos de gestión o planificación específicos y los compromisos de acción parecen ausentes.

Palabras clave: montañas, Galicia, Geografía, Ordenación del Territorio, paisaje, cartografía, historia del pensamiento geográfico. 


\section{ABSTRACT}

Transformative Geographical Readings on the Galician Mountains: from the «difficulty of their study» to considering them a spatial "periphery in deep economic depression»

This work analyses how the Galician mountains can be seen to be a constructed reality created by the discipline of Geography and through the applied and policy-focused approach of planning. It begins by a theoretical and methodological review of the literature on the academic, social, political or cultural representations of the mountains. The first analytical section focuses on the haphazard representation of mountains in Galicia during the period before the advent of formal geographic and cartographic approaches. The paper then considers the 1970s and 1980s, a key period when institutionalised Geography developed a normative understanding of the Galician mountains, which is still current. The paper concludes by outlining recent research and planning debates around the Galician mountains that conclude that the areas are seen as peripheral and marginal suffering from a lack of specific spatial management, planning and implementation mechanisms.

Keywords: Mountains, Galicia, Geography, Regional Planning, Landscape, Cartography, History of Geographical Thought.

La asociación de Galicia con las montañas es un lugar común desde hace siglos. Ya un soneto de Góngora de 1609, por cierto muy criticado por Castelao (1944) debido a su ostensible gallegofobia, comenzaba con el verso «iOh montañas de Galicia!». En este sentido, la imagen de Galicia dominante hoy en día en los medios de comunicación, los libros de texto o las conversaciones cotidianas es la de una región montuosa e inaccesible, con fuertes pendientes y desniveles, una topografía accidentada y accidentes orográficos por todas partes. Sin embargo, es cierto que se trata de una percepción general hasta cierto punto estereotipada, de entrada porque existen zonas en Galicia notablemente llanas (A Limia, Terra de Lemos, A Terra Chá -la «tierra llana», literalmente-, etc.), por lo que la correspondencia de la imagen con la topografía observable es matizable. Por otro lado, las alturas en Galicia no llegan a ser demasiado elevadas, ya que a duras penas ultrapasan los $2.000 \mathrm{~m}$ en su máxima cota. Este hecho, si se contrapone a otras regiones y naciones con parte o la totalidad de su territorio en el Pirineo o los Alpes, nos revela unas montañas comparativamente modestas, que para nada entran dentro del prototipo alpino de picos puntiagudos que se suele asociar a las mismas. En definitiva, la percepción de Galicia como territorio montañoso puede ser discutible en múltiples sentidos y se impone la necesidad de referirse a las montañas como realidad construida, en función de las representaciones de distinta naturaleza que han mediado en dicha construcción.

En concreto, en este trabajo nos dedicamos fundamentalmente a la aportación que ha realizado la Geografía como disciplina, y la Ordenación del 
Territorio como su vertiente práctica más aplicada, a la construcción de la idea de montaña en Galicia. No se trata de señalar qué montañas hay en Galicia, sino cómo estas han sido percibidas académicamente y de qué modo han ido evolucionando los discursos a su alrededor, en particular cómo se ha conformado una determinada visión sobre la organización del relieve gallego en las últimas décadas que ha tenido una impronta considerable. Aportamos, así pues, un enfoque novedoso, que ontológicamente no se refiere a las montañas gallegas en sí -por otro lado, tal y como se verá, poco estudiadas y nunca objeto de planes territoriales específicos-, sino a las representaciones que de ellas se han efectuado. Nuestra hipótesis de trabajo es que la Geografía académica ha tenido un rol activo en la creación de un discurso sobre las montañas gallegas, sobre su organización y sobre sus atributos territoriales (físicos y humanos), en paralelo a lo que ha sucedido en otros contextos que tendremos ocasión de revisar. Para alcanzar nuestro objetivo de estudio, nos valemos desde un punto de vista epistemológico de la perspectiva desarrollada por Debarbieux y Rudaz (2010) para analizar la construcción de la categoría montaña y que ya se ha aplicado sobre todo al caso francés, pero no únicamente.

El trabajo empieza por una primera sección en la que planteamos un abordaje teórico-conceptual a las representaciones de las montañas. A partir de este primer apartado, el resto de los contenidos se refieren a Galicia como caso de estudio específico. De entrada revisamos la visión de las montañas gallegas en la cartografía y el conocimiento geográfico preacadémicos, para después detenernos en las décadas de 1970 y 1980, momento clave en el que creemos que se fija la lectura preponderante de las mismas por parte de la Geografía institucionalizada. A continuación, explicamos los desarrollos investigadores y en términos de ordenación del territorio producidos desde entonces, análisis que conduce a un breve apartado final que, a modo de conclusiones, valora la trayectoria gallega en relación al núcleo teórico-conceptual planteado al inicio del trabajo.

\section{LAS REPRESENTACIONES DE LAS MONTAÑAS}

Las montañas constituyen, sin duda, objetos geográficos materiales identificables en la superficie terrestre. Algunas de las mejores páginas de la Geografía se han dedicado a ellas, en una larga nómina de autores que desde hace siglos, por ejemplo, se han preocupado en sus corologías por encontrar y describir el pico más alto de un determinado territorio, sobre todo desde la invención del barómetro a mediados del siglo xvII. Sin embargo, no se pueden obviar las distintas representaciones construidas alrededor de las montañas, cambiantes en el tiempo y en el espacio. Una prueba evidente de ello es la alteración de la denominación de una cumbre tan emblemática como el Mont Blanc en el setecientos ilustrado: de llamarse «Montaña Maldita» durante los siglos anteriores 
pasó al actual topónimo «Monte Blanco» (Nogué, 2005; Martínez de Pisón, 2004). Esta substitución debe interpretarse como una modificación de calado en la percepción de ese pico, paralela a lo que sucedió en una dirección parecida en tantas otras montañas del mundo occidental, aunque sin duda las demás tuvieron un despertar rezagado en relación a los Alpes -no es de extrañar, por lo tanto, que se convirtieran en canon de todo lo montano (alpinismo, esquí alpino, vegetación alpina y subalpina, etc.). Las montañas siempre habían estado allí, pero hubo un momento en el que se empezaron a considerar, observar, dibujar, poner de moda, relatar, escalar, etc. Se produjo, de este modo, la «invención de la montaña», en acertada expresión, entre otros autores, de Frolova (2006), que dependiendo de la sociedad tuvo lugar cronológicamente de forma más o menos tardía a partir del siglo XVIII.

De hecho, Humboldt, padre de la Geografía moderna, asoció siempre sus explicaciones geográficas - de las montañas, pero lo mismo podría ser dicho de otros ambientes tales como los desiertos o las estepas- a una plétora de imágenes sensibles, estéticas y sentimentales.

Apenas se llega a la cima del peñasco [en la zona de Atures, municipio del actual estado venezolano de Amazonas], sorprende al espectador el vasto cuadro que despliega la comarca que lo rodea. Del espumoso cauce del río levántanse colinas cuajadas de bosques: del otro lado y más allá de la orilla occidental, descansa la vista en la inmensa pradera del Meta, apareciendo en el horizonte como nube amenazadora la montaña de Uniama. [...] El barranco está rodeado de montañas cuyas redondeadas cúspides sostienen enormes trozos de granito de 13 a 16 metros de diámetro, que parecen tocar en solo un punto la base sobre que descansan, como si la más ligera conmoción del suelo fuera a precipitarlos en el abismo. (Humboldt, 1828 [ed. 2003]: 192).

¿Puede soslayarse en la obra de Humboldt la dimensión de las representaciones a la hora de analizar su estudio de las montañas? Nos parece que no. Sin embargo, ha ocurrido con frecuencia, de modo que la obra de este autor se ha visto amputada cuando ha interesado primar solo la perspectiva objetivista (Ortega Cantero, 1987), por ejemplo, en cuanto a la geomorfología o a la biogeografía. Este hecho es muy relevante, ya que hasta hace relativamente poco la consideración geográfica de las montañas rechazaba por sistema lo subjetivo, lo perceptual y lo iconográfico. Y ello a pesar de evidencias patentes como las del «nuevo» topónimo del Mont Blanc y las otras «invenciones» de montañas, o de la concepción integrada que poseía Humboldt de la materia. Un claro ejemplo de ello en España es el abordaje de las montañas practicado por el CIMA (2005a), muy completo en la definición de toda la rica diversidad de términos «objetivos» asociados (alta montaña, bancales, brañas, cumbres, esquí, macizos, pastoreo, periglaciarismo, etc.), pero sin concesiones a la dimensión de las representaciones individuales y sociales. 
Es también altamente ilustrativo el que una cuestión fundamental sobre las montañas -cuántas son y cómo se ordenan- se venga continuamente dando por sentada sin el menor género de dudas. Esto es, cuanto menos, sorprendente, pues ha sido la Geografía académica la que ha tendido a fijar la denominación y la organización de sierras, cordilleras o picos, un proceso de construcción del conocimiento que no ha merecido prácticamente atención. Así, se ha reproducido libro de texto tras libro de texto que en un territorio dado «existen» unas determinadas unidades montañosas, cuando su «existencia» misma depende activamente de la forma de clasificar y ordenar por parte de la Geografía (o disciplinas análogas). Vilà Valentí (1991) lo tuvo bastante claro en su día para el contexto catalán:

En un largo período, hasta la centuria pasada, el relieve catalán es presentado y descrito de una forma confusa, incluso caótica. [...] Las primeras clarificaciones no aparecen hasta mediados del siglo pasado. [...] Se trata, claro está, de geólogos y cartógrafos, que con sus trabajos de campo irán aclarando las características verdaderas [sic] del relieve catalán. [...] Ya en nuestro siglo, geólogos y geógrafos ayudarán a definir las unidades fundamentales del relieve catalán y mostrarán no tan solo la existencia [sic] de unos determinados volúmenes, formas y altitudes sino que señalarán, en cada caso, unas originalidades más profundas, arrancando de unas ciertas características comunes de evolución geológica, petrográfica y tectónica. (Vilà Valentí, 1991: 9-10). ${ }^{1}$

De acuerdo con Sacareau (2003), la Geografía académica francesa comenzó a interesarse por las miradas sobre las montañas y la importancia de los discursos y las narrativas para aproximarse a ellas a partir de la década de 1980. Según esta autora, las representaciones a estudiar desde la perspectiva geográfica comprenden tanto las percepciones de las poblaciones que viven en las montañas (o las utilizan o actúan en ellas) como las de los científicos de distintos tipos que las consideran un objeto de análisis. Para ambos grupos parece necesario identificar de qué modo van variando sus percepciones. Todo ello ha permitido transitar de análisis geográficos que solo entendían -y aún entienden en numerosos casos- la montaña como evidencia física y humana, a privilegiar la idea de montaña como representación.

En España, algunos de los primeros ensayos que adoptaron este abordaje para un ámbito montañoso en particular fueron escritos por Roma $(2002,2004)$. Este autor analizó cómo las imágenes de Montserrat y de las montañas catalanas en general han ido variando a lo largo de los siglos. De este modo, Roma $(2002,2004)$ probó la presencia de un tránsito intelectual desde la consideración de Montserrat o de los Pirineos como lugares temibles y horrorosos a su elevación a símbolos nacionales catalanes. Este proceso discurrió en paralelo

1. Esta y todas las traducciones siguientes son nuestras. 
a un potente flujo montañero y excursionista, a partir del siglo XIX, y de una fuerte convicción proteccionista que acabó desembocando a lo largo del xx en la explosión de figuras de conservación de la naturaleza y del paisaje centradas en los ámbitos montañosos, lo que ha dado lugar a una selección de lugares simbólicos que es totalmente ideológica (Nogué, 2005: 164). No se trata, ha recalcado Roma (2004), de que cambien las montañas físicamente desde el punto de vista geográfico, que obviamente sí que se transforman por su dinámica natural y por procesos tales como el despoblamiento rural, sino que su percepción va variando de forma considerable a lo largo del tiempo. Otros trabajos posteriores, como el de García Álvarez (2013) sobre Covadonga y otros paisajes de montaña, apuntan en la misma dirección, en ese caso en relación a la identidad y el nacionalismo españoles.

Sin duda, la obra reciente que mejor ha sistematizado todos los avances investigadores en la línea de estudio de las montañas como representaciones individuales y sociales es la de Debarbieux y Rudaz (2010). Se trata de una publicación compleja, imposible de resumir aquí, pero que cabe destacar entre otras razones porque se fundamenta en un alto rigor conceptual acerca de la categorización de los objetos geográficos, lo que ya aparecía en aportaciones anteriores (vid. Debarbieux, 2004). De entrada, estos autores han argumentado que las montañas han de entenderse como un concepto relativo, ya que dependen de la mirada de una determinada colectividad para relacionarse con su entorno: algunos pueblos perciben pequeños cerros o elevaciones próximas como «montañas», mientras que otros ante relieves de entidad no utilizan esa denominación en su lengua vernácula. Más allá de esta cuestión, que esos expertos consideran meramente fenomenológica, en el siglo XVIII se produjo una evolución semántica transcendente por la que las montañas pasaron a ser una categoría científica y política.

Sobre la primera de dichas categorías, puede subrayarse la importancia que adquirió la cartografía para representar las montañas, lo que ha ayudado a fijar determinadas formas de entender la organización del relieve, incluso con prejuicios y malentendidos. En relación a la montaña como categoría política, cabe afirmar que las montañas han sido una pieza estratégica para unos estadosnación deseosos de demarcar de forma estricta sus fronteras con unas premisas pretendidamente sólidas; además, para muchos nacionalismos la montaña se ha convertido simbólicamente en un lugar de «refugio ideal» para explicar el origen y las esencias de las naciones, como Nogué (2005) acertadamente ha estudiado en el caso del nacionalismo catalán -pero ello es también relevante en el caso de Covadonga y los Picos de Europa, convertidos en símbolos patrios de un supuesto origen nacional (García Álvarez, 2013). A posteriori, en el ámbito de las políticas públicas, las montañas se han consolidado como una materia específica en lo referente a la programación de directrices de ordenación 
y medidas de gestión: parques nacionales, planes regionales de montaña, etc., hasta el punto de que las montañas han saltado de escala de intervención y, en las últimas décadas, se observa una lectura paneuropea, e incluso global, de las mismas. Obras como la de Price, Jansky y Iastenia (2004), auspiciadas por las Naciones Unidas, son una prueba fehaciente en esta dirección.

\section{«LA DIFICULTAD DE ESTUDIO DE LAS FORMAS COMPLICADAS». ${ }^{2}$ LAS MONTAÑAS EN LA CARTOGRAFÍA Y LA GEOGRAFÍA PREACADÉMICAS}

Como sucede en otros muchos lugares, las informaciones sistemáticas más antiguas de tipo geográfico sobre el territorio gallego nos han llegado más a través de la cartografía que de obras monográficas de tipo corológico. Excluyendo las cartas náuticas, los primeros mapas de Galicia propiamente dichos proceden del tránsito de los siglos XVI y XVII (Méndez Martínez, 2005, 2001). Existe un consenso en señalar que el mapa de Hernando de Ojea de 1603 es el primero transcendente, en la medida en que fue realizado ex professo para Galicia y difundido mediante atlas coetáneos y posteriores, dando lugar a una serie de mapas que en lo fundamental optaron por reproducirlo durante dos siglos.

En las primeras ediciones, ${ }^{3}$ Ojea señaló únicamente un ámbito montañoso amplio en Galicia en su margen sureste, representado con un área poblada de dibujos de cerros o colinas. En algunas ediciones ese ámbito apareció fuera del límite de Galicia y en otras dentro, haciendo frontera en una disposición meridiana desde Ponferrada hasta Puebla de Sanabria e incluso adentrándose en Portugal, de modo que parece poderse inferir una localización como «frontera natural», tal y como sucede en otros muchos casos (Debarbieux y Rudaz, 2010). El topónimo que Ojea fijó para ese ámbito fue «Tierra de Cabrera». La Cabrera es hoy en día un territorio relativamente bien delimitado del suroeste de la provincia de León; sin embargo, estos primeros mapas apuntan a una geografía más amplia para el mismo, en la que se incluye el conjunto de los Montes de León tal y como son comúnmente conocidos en la actualidad, cuyas estribaciones por el oeste culminarían en la Pena Trevinca $(2.127 \mathrm{~m})$, techo de Galicia. En otro orden de cosas, el mapa de Ojea y sus derivados situaban la línea de frontera de Galicia más allá de la actual, de modo que al menos la mitad occidental del Bierzo y As Portelas (Portillas o Alta Sanabria en su denominación castellana) aparecían localizadas dentro del territorio gallego. Ojea escribió un pequeño

2. Otero Pedrayo (1926: 10-11) empieza hablando de la «dificultad de estudio» del relieve gallego en su capítulo dedicado a este tema en su conocida Sintese xeográfica de Galicia y se refiere específicamente a «las formas complicadas» presentes en las montañas de A Fonsagrada, Os Ancares y O Courel, pero esta idea sería sin duda generalizable a su visión del conjunto.

3. Utilizamos dos libros como corpus de cartografía histórica: Méndez Martínez (2005) y Lorenzo y Sáez (1989). 
texto para el reverso de su conocido mapa, que nunca llegó a editarse (Bouza, 2009). Al haber permanecido inédito, no puede ser considerado estrictamente un antecedente -sí, en cambio, su mapa- de las representaciones de las montañas gallegas. Sin embargo, posiblemente constituye la primera descripción territorial de Galicia con una referencia directa a las montañas.

Es tierra por la mayor parte montuosa con muchas y muy hermosas valles que yacen entre sierras, con que al modo de red entretexiendose las unas con las otras viene a fenecer en ella un sajo de los montes Pirineos (Manuscrito de Hernando de Ojea circa 1603 conservado en la Bancroft Library de la Universidad de California transcrito por Bauza, 2008: 38).

Las colecciones de atlas derivados de Mercator y Blaeu, compiladas y difundidas a lo largo del siglo XVII, aun recogiendo en lo fundamental la interpretación de Ojea, fueron realizando aportaciones de interés en lo que a relieve se refiere. La primera consistió en que el muro montañoso fronterizo del sureste se fue extendiendo de forma progresiva hacia el noreste, de modo que se consolidó una representación de Galicia como separada de León y Asturias por una especie de cordillera de disposición meridiana. Dicha cordillera actuaría de «frontera natural» y en parte se situaría más hacia oriente, por ejemplo en el Bierzo, que se dibujaba separado de la Meseta mediante montañas pero que, en cambio, se daba a entender que no tenía impedimentos orográficos con Galicia. Es interesante subrayar esta forma de representar Galicia, porque se fue fijando la idea de que por el este está separada mediante montañas del resto de los territorios peninsulares, idea que no es más que una construcción cultural. Algún mapa cartografió una continuidad en perpendicular de estas montañas dentro de Galicia, en una dirección latitudinal, sobre todo en la divisoria entre A Mariña y A Terra Chá, en todo lo que sería O Xistral y Serra de Meira, entre otros, como si la Cordillera Cantábrica-que leyendo a Ojea, podemos suponer que se consideraba por aquel entonces una mera continuación del Pirineo- penetrase en Galicia hasta el Golfo Ártabro.

La segunda nueva aportación respecto del mapa de Ojea la introdujo la colección de Blaeu, cuyo primer ejemplar de Galicia data de 1635, y consistía en ampliar ostensiblemente la distribución montañosa de Galicia hasta cubrirla de montañas en más de la mitad del territorio. Las montañas orientales se siguieron representando, a lo que se sumó una inmensa orla montañosa que parecía desprenderse desde el noreste de Galicia hacia el suroeste (de A Fonsagrada a Baiona) y desde el noreste hacia el oeste, hasta Fisterra y el Monte Pindo que, aunque no rotulado con el topónimo, es la montaña más relevante que en estos mapas se ubicaba en el ámbito noroeste de Galicia. Incluso en algún mapa derivado de Ojea, como en el de Cantelli da Vignola (fechado en 1696), directamente toda Galicia se cubrió de montañas. Se prodigó, por lo tanto, una interpretación de Galicia como un país montañoso sin jerarquías, un caos de montañas 
sin orden ni concierto, lo que sin duda conecta con la literatura española de la época, que así la percibía (Murado, 2008).

En el siglo XVIII se produjeron avances cartográficos, como la serie de la España sagrada de Henrique Flórez (con mapas de diócesis de la década de 1760) y el conocido mapa de Galicia de Tomás López de 1784. A nuestros efectos, destaca la multiplicación de montañas que se observa en estos mapas, de modo que toda Galicia se cubrió por norma de las mismas y, por lo tanto, parece extenderse la visión de Galicia como un complejo montañoso. Se hace difícil encontrar una jerarquía; no obstante, en el mapa del obispado de Ourense, por ejemplo, se puede observar cómo se marcaron unas sierras principales en dirección noroeste-sureste que lo delimitarían respecto al de Astorga (Queixa, San Mamede, Seca, Segundeira, etc.) y otras zonas que actualmente no calificaríamos de sierra o de montaña (Montañas de Riós) se indicaron entonces como tales. En el mapa de López la profusión de montañas dificulta inferir una organización del conjunto, aunque cabe destacar que el mapa realzó determinadas montañas de forma ostensible, en concreto las del margen sureste de Galicia. En ese sector la frontera ya se ajustaba más a la actual (aunque Vilanova da Serra -o Villanueva de la Sierra en toponimia desfigurada-, actualmente provincia de Zamora, aparecía cartografiada dentro de Galicia) y desaparecía la denominación de La Cabrera para ese conjunto, emergiendo, por primera vez, el topónimo del pico de la Pena Trevinca. Además, las sierras de la divisoria interdiocesana Ourense-Astorga antes indicadas se representaban notablemente engrandecidas, lo que seguramente se explica porque el mapa de López es de gabinete (Méndez Martínez, 2005, 2001) y por lo tanto copiaba el diocesano correspondiente de la España sagrada.

La indefinición acerca de las montañas más altas de Galicia se mantendría aún unas décadas más, tal y como evidencia uno de los primeros geólogos, el alemán Schulz, que se ocupó de nuestro territorio de estudio:

No he averiguado la altura de las diferentes cordilleras respecto al nivel del mar, porque en mis viajes no hubo lugar para tales observaciones; pero en general puedo decir que las sierras de Galicia no son de una elevación estraordinaria, no llegando ninguna á la nieve perpétua. Solo los Picos de Ancares y la Peña Trevinca, ambas sobre los confines orientales de Galicia, conservan alguna nieve hasta mediados del estío; á estas siguen en altura la cumbre de San Mamed y la gran sierra del Invernadero, cuyas cimas tampoco son transitables sino en el rigor del verano, despues siguen la sierra de Queija, el pico del Faro en el Cebrero, la cordillera del Suido, el Cajado, el monte Faro sobre Chantada y otros varios; las demas son accesibles la mayor parte del año para el ganado, y muchas son habitables hasta cerca de sus cumbres (Schulz, 1835: 7-8; mantenemos la ortografía original). 
Este texto también pone de relieve la ausencia de una explicación organizada del relieve gallego, dándose a entender en la redacción una cierta dispersión: las sierras más altas parecían localizarse a noreste y sureste, a más de $50 \mathrm{~km}$ de distancia entre ellas, y después las siguientes se distribuían de forma aleatoria por el territorio, como puntos aislados. En otro orden de cosas, esta cita podría ser interpretada como una evidencia de la Pequeña Edad del Hielo de la edad moderna, pues las condiciones que relataba son ostensiblemente más frías que las actuales.

El cambio más relevante en el panorama cartográfico gallego lo produjo el mapa de Domingo Fontán, ya acabado en 1834 pero no publicado hasta 1845 (Méndez Martínez, 2005, 2001), convertido en símbolo de Galicia por autores posteriores tales como Otero Pedrayo (López Sández, 2008; Murado, 2008). Para el relieve, el uso de normales hizo del mapa un producto estéticamente muy conseguido. Sin embargo, esta representación dificulta la comprensión de la topografía. En todo caso, la lectura de conjunto del mapa -de dimensiones gigantescas, pues se compone de doce fragmentos- transmite un país muy rugoso, donde las mayores pendientes se concentran en el tercio más oriental. Queixa y Segundeira (esta última en Zamora, pero el mapa de Fontán se adentró en las provincias limítrofes para estudiar la mejor manera de construir los modernos accesos a Galicia) emergieron como dos ámbitos substantivos elevados respecto al entorno; la forma de representarlos, una suerte de altiplano, era exagerada, pero reiteraba de algún modo la visión del extremo sureste de Galicia como la alta montaña gallega.

De acuerdo con Ortega Cantero (1997), Dantín Cereceda fue una figura clave para la renovación y consolidación de la lectura geográfica de la Península Ibérica. En particular, revistió especial transcendencia su difundido Resumen fisiográfico de la Península Ibérica, «en su momento, en el ámbito de la Geografía física, una obra fundamental» (Ortega Cantero, 1997: 10). En este libro, cuya primera edición data de 1912, las montañas de Galicia aparecían profusamente tratadas. De entrada, empezaba afirmando que las montañas gallegas y las portuguesas (del Norte de Portugal, mejor dicho) son las mismas (Dantín Cereceda, 1948: 36), a las que se refería como «montañas galaicas» (p. 44) o «macizo galaico-lusitano» (p. 45).

Esta unidad aparecía caracterizada de modo genérico por «su relieve orográfico, más o menos montuoso, si no de gran altura, de variada accidentación en sus montañas» (Dantín Cereceda, 1948: 45). Sin embargo, curiosamente, su unicidad era explicada en términos de diferencias con los ámbitos adyacentes, no tanto por su homogeneidad interna, que no era obvia: «aparecen con tan evidente unidad que parecen bastar a constituir una región de las más naturales, [pero] acusan una inconexión tal, que es difícil señalar en ellas un rasgo general, ni apenas las relaciones que las unen» (Dantín Cereceda, 1948: 70). Nuestro 


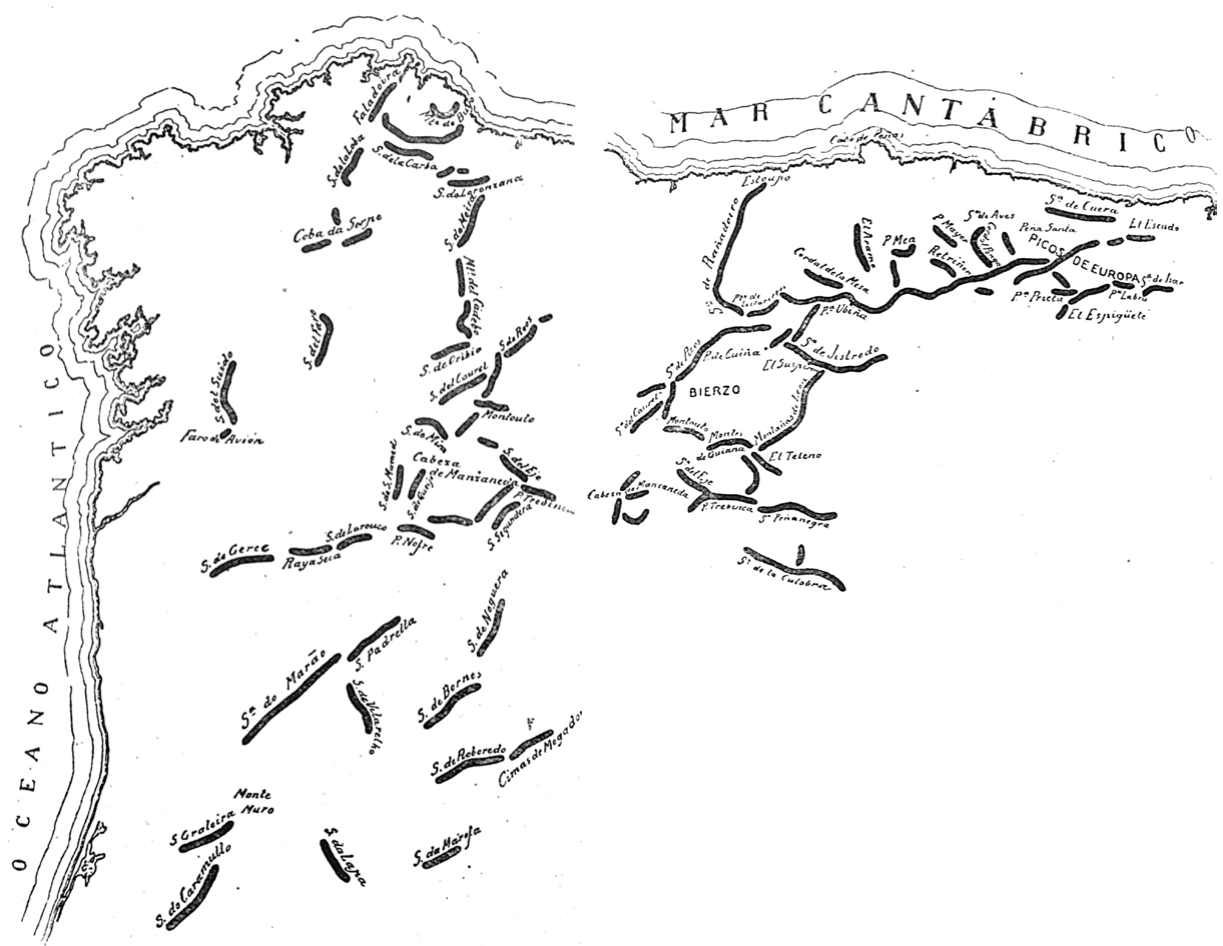

Figura 1. La organización en alineaciones del Macizo galaico-lusitano y de las Montañas cantábricas según Dantín Cereceda. Fuente: Dantín Cereceda (1948: 66, 71).

autor excluyó de este complejo las montañas del sureste gallego, precisamente las más altas de Galicia, que consideraba parte de las Montañas Cantábricas, en las que también englobó O Courel y Os Ancares. Por el noreste, en cambio, el Rañadoiro, ya dentro de Asturias, fue utilizado para marcar la diferencia entre las Cantábricas y el Macizo galaico, de modo que la «frontera» entre unidades fisiográficas se desvinculaba totalmente de la línea política, ya sea porque penetrasen las Cantábricas en Galicia o porque el Macizo gallego se adentrase por Asturias.

Sea como fuere, el geógrafo atribuía a Cabeza de Manzaneda $(1.778 \mathrm{~m})$, que cartografiaba tanto en el mapa de las Cantábricas como en el del Macizo Galaico, el papel clave de «núcleo del que haremos irradiar todo el conjunto de las Sierras que accidentan el suelo gallego» (Dantín Cereceda, 1948: 70). De este modo, Cabeza de Manzaneda era considerada un hito estructurador del relieve gallego. A partir de una cartografía de alineaciones, de esa altura hacía desprender dos ramales en el territorio gallego. Uno, hacia el suroeste, acabaría en el Xurés-Gerês, dibujando incluso entre esa sierra y el Larouco 
una imaginaria sierra de la «Raya Seca» (sic) - ¿tal vez Dantín Cereceda tenía delante el mapa de Fontán, que indica ese topónimo para referirse a la frontera gallego-portuguesa interior? La disposición latitudinal de esta alineación era una mera apreciación subjetiva, pues Larouco es una sierra de orientación meridiana. Otro ramal desde Cabeza de Manzaneda, y siempre dentro de Galicia, iría hasta el noreste del país, conectando en O Courel con las Cantábricas y dibujando en su parte más al norte una especie de arco que cerraría la Terra Chá por todos los costados excepto el meridional, por el que obviamente fluye el Miño. Se trataba, en definitiva, de una primera propuesta de organización del relieve gallego, creemos que sin precedentes como tal, que de algún modo permitía superar la larga fase del «todo montañoso» caracterizada por una imposibilidad de obtener una imagen ordenada y coherente. Sin embargo, la organización de Dantín Cereceda se basaba en una selección arbitraria de algunos cordales de montañas, y no otros, para obtener unos trazados imaginarios que se desprendían, de modo opinamos que forzado, de Cabeza de Manzaneda.

La Geografía gallega encuentra en la figura de Ramón Otero Pedrayo un emblema mayúsculo, aún insuperado como referente simbólico. No obstante, los geógrafos actuales han sido extremadamente críticos al evaluar su obra como contribución al avance del conocimiento del territorio gallego. Así, Santos (1999: 1346) opinaba que su vocación geográfica «se debió seguramente a la necesidad que tenía el nacionalismo gallego de abarcar todas aquellas facetas de ciencia que fueran útiles para la consolidación de su proyecto», y en este sentido habló de «invento» de Otero Pedrayo como geógrafo (p. 1353), lo que debe ser considerado una opinión cuando menos provocadora. Asimismo, indicaba este autor que su calidad no fue nunca pareja a la de Manuel de Terán en España o Pau Vila en Cataluña ${ }^{4}$ (Santos, 1999: 1345), por lo que no generó estrictamente una lectura geográfica del territorio gallego. Este hecho, unido a que no originó una escuela geográfica, en parte porque no tuvo tiempo de formar discípulos en el período que ocupó su cátedra en Santiago de Compostela (1950-1958), y al triunfo del pensamiento geográfico antitético que se impuso en la universidad compostelana después de su jubilación, invalidaría tal vez que le dedicásemos nuestra atención. Sin embargo, pensamos que es esta una buena oportunidad para aproximarnos a su obra como geógrafo y, por otro lado, nos parece que su transcendencia es tal en la cultura gallega (no tanto en la Geografía, pero desde luego sí en el campo de la literatura y en las humanidades en general) que su construcción paisajística del territorio, como realidad inmaterial y subjetiva, no

4. Vilà Valentí (1991) explicó en su día que la repartición tripartita (Pirineos, Depresión Central y Catalánides) es la lectura preponderante, obtenida después de una larga sublimación protagonizada por el relieve catalán. No es ocioso señalar en este punto que Pau Vila estructuró su conocido, y muy popular, Resum de Geografia de Catalunya aparecido por fascículos entre 1928 y 1936 en tres bloques, uno dedicado a cada uno de esos tres ámbitos de relieve. 


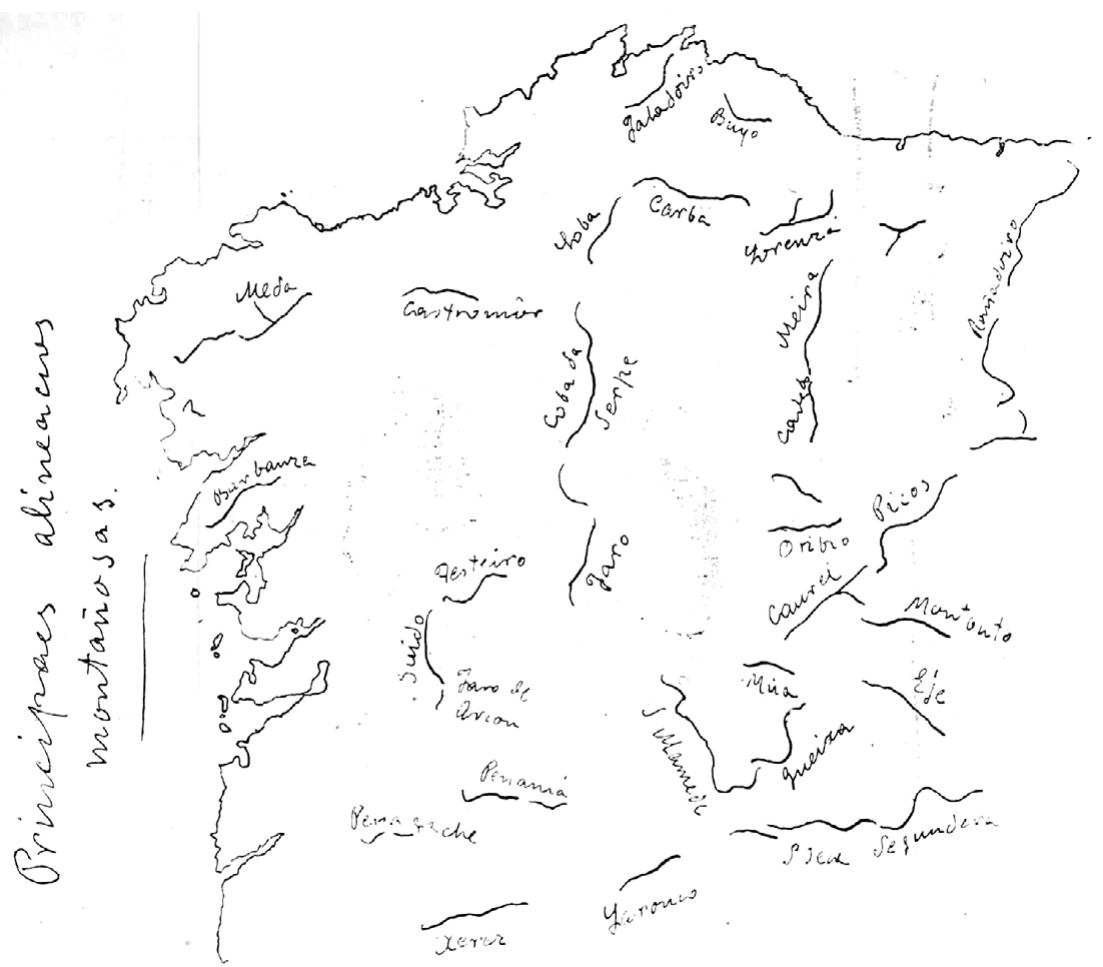

Figura 2. Las montañas de Galicia. Fuente: Otero Pedrayo (1926: 21).

puede omitirse. Así lo ha defendido desde el campo de los estudios literarios López Sández (2008), entre otros autores, y lo hemos abordado de forma conjunta desde la Geografía y los estudios literarios en Paül y Labraña (2013).

Otero Pedrayo (1926: 5) afirmó que su Síntese xeográfica de Galicia «solo responde al deseo que siente el autor de que se haga un libro popular de Geografia gallega», de lo que debemos inferir su voluntad didáctica y pedagógica. Pretendía de este modo «ensayar una descripción, lo más clara posible, de las formas [...] que se combinan en el relieve» (Otero Pedrayo, 1926: 10). Para ello, «partiendo del principio general de la unidad (geológica y geográfica) del país gallego-duriense» (op. cit.), lo repartió en cuatro partes que grosso modo se corresponden con las cuatro provincias vigentes. La explicación de veinte páginas que sucedía a esta idea general enumeraba y describía gran cantidad de sierras y montañas articuladas en estas cuatro grandes regiones, sin explicar cómo se articulaban entre ellas o de qué modo general se podría hablar de organización. Emergía de nuevo, en este sentido, una imagen caótica del relieve gallego, que se retrotraía de facto a fases anteriores del conocimiento geográfico de Galicia. El propio mapa que acompañaba el texto, que bebía del de Dantín 
Cereceda, transmitía de forma gráfica esta idea de montañas por todos lados y sin jerarquías ni orden. De hecho, lo que básicamente hizo Otero Pedrayo en relación al mapa precedente fue aumentar el número de sierras representadas como «alineaciones», por lo que la imagen estructurada del anterior -aunque arbitraria- se diluyó. En este sentido, el análisis de la parte de relieve de Otero Pedrayo (1926) nos permite concordar con la observación de Santos (1999) al respecto de la calidad mejorable de la geografía del geógrafo gallego más egregio.

En relación a la imagen oteriana de las montañas gallegas, cabe señalar su innegable capacidad creativa, aunque tenemos dudas fundamentadas de que muchas de sus representaciones se basasen en una percepción directa sobre el terreno, sino que más bien parecen ser recreaciones literarias desde la distancia -véase lo que explicamos en Paül (2011) para la literatura de Otero sobre los Montes do Invernadeiro, pero estamos persuadidos de que algo parecido sucedió en el caso de Pena Trevinca, a la que el insigne geógrafo le dedicó algunas páginas, y que posiblemente nunca pisó. Otero Pedrayo (1955: 42) propuso interpretar Galicia mediante «cinco pisos o composiciones de paisaje»: marina, ribera, bocarribera (bocarribeira), montaña y sierra. Es curioso comentar que, de las veinte páginas del ensayo al respecto, sólo las últimas cinco fueron dedicadas a montañas y sierras y, en concreto, algo menos de la última era consagrada a las sierras, que cabe interpretar en clave oteriana como la montaña a efectos nuestros -sus montañas eran para él el monte o superficie inculta de cada una de las parroquias gallegas (Otero Pedrayo, 1955: 53). De entre los caracteres de las sierras gallegas, destacamos la siguiente cita:

[En relación al tema de la vegetación,] los pinos con el desarrollo de los yermos y de las gándaras, las aguas o indecisas en las zonas llanas de las alturas [chairas] o incisivas en las vertientes, en el ritmo el mayorazgo del factor cósmico, telúrico con el decaimiento del tono vegetal, el largo dominio del invierno, las formas agrícolas muy ceñidas, elementales y regias [...]. (Otero Pedrayo, 1955: 57).

Este fragmento nos transmite que las sierras son para el autor paisajes sin agricultura donde dominan los factores naturales. Teniendo en cuenta que para Otero Pedrayo (1955: 57) «Nuestra cultura es cultura de ribera o de bocarribera» -es decir, agraria-, la montaña era representada como rara avis que no cumplía con el canon ideal del paisaje gallego por él establecido. Dicho canon tiene una genealogía rosaliana (Paül y Labraña, 2013; López Sández, 2008), pero en todo caso nos interesa subrayar que el padre de la Geografía gallega tenía los paisajes montanos en baja estima, al menos en relación a los agrarios. Su discurso se centró siempre en el paisaje como creación campesina, valores que él vio sobre todo cristalizados en las formas agrarias dulces de la Galicia media, ni costera ni de montaña. De hecho, llegó a escribir que «en el espíritu duerme -en el espíritu 
de los campesinos y marineros- un amor a lo cósmico y sencillo de la montaña» (Otero Pedrayo, 1955: 57): es decir, que la vinculación de la galleguidad con la montaña sólo podía ser entendida en términos oníricos, pues en la vida real los paisajes de las tierras altas de Galicia serían poco más que una ensoñación lejana. En definitiva, a diferencia de otras muchas creaciones nacionales que pusieron las montañas en el centro de su cosmovisión -recuérdese el caso catalán analizado por Nogué (2005) o Roma $(2002,2004)$ - la gallega, presidida sin duda por Otero Pedrayo, ha tendido a minusvalorarlas. No se trata de que no haya montañas en Galicia, es que no se han ensalzado y significado como en otras culturas.

«Pueden distinguirse Las grandes Unidades del RelieVe Gallego». 5 La DETERMINACIÓN DE LAS MONTAÑAS GALLEGAS POR LA GEOGRAFÍA ACADÉMICA

La década de 1970 fue clave para acometer el primer intento académico serio de caracterización del territorio gallego y, por supuesto, de sus montañas. Esta década se acompañó de una serie de procesos administrativos y de la publicación de estudios novedosos que mantendrán su fuerte influjo sobre la Geografía de Galicia durante las décadas siguientes, tal y como ya señalamos hace algunos años (Torres y Lois, 1999). Así, este decenio permitió la consolidación de un Departamento de Xeografía en la Universidade de Santiago, con un equipo de profesores e investigadores relativamente estable, que en su mayoría ha continuado en activo hasta hace unos pocos años. Frente a este núcleo institucional, el tránsito de los 1970 a los 1980 vio florecer un pequeño núcleo muy activo de geógrafos críticos, en principio al margen del departamento, y cuyas referencias fueron Pérez Alberti y Souto, dos jóvenes profesores de instituto que elaborarían libros y materiales «alternativos» a los académicos, tales como Pérez Alberti (1979) o Souto (1980).

Por otro lado, en los años 1970 se consolidó la interpretación de Galicia como un territorio rural y atrasado, que había cambiado muy poco a lo largo de su historia reciente, en una lectura compartida desde diversos puntos de partida por el economista Beiras y los geógrafos García Fernández y Bouhier. Así, la obra $O$ atraso económico de Galicia profundizaba en las causas del retraso del país, entre las cuales la expropiación del excedente financiero, la colonización interior y la emigración constituían algunos de sus exponentes más destacados (Beiras, 1972). En una línea paralela, García Fernández (1975) y Bouhier (1979) se esforzaron en analizar geográficamente el «viejo complejo agrario», en conocida expresión de Bouhier, y las causas de su (aparente) tendencia al inmovilismo, así como sus formas más características de organización del espacio

5. Miralbés (1978: 197) empieza de este modo la descripción de las cuatro grandes unidades de relieve que propone distinguir en Galicia. 
cultivado y de las amplias superficies de monte existentes -que en más de una ocasión, dicho sea de paso, se explicaban en términos de montaña. Por último, y quizás con una influencia más indirecta, a partir de finales de los 1960 una serie de autores foráneos, fundamentalmente franceses, realizaron sus tesis doctorales o importantes monografías centradas en Galicia (Bertrand, 1992; Mounier, 1979; Nonn, 1969; Huetz de Lemps, 1967; Birot y Solé, 1953). Su obra fue menos conocida que las anteriores por el gran público; sin embargo, una serie de autores que pudieron acceder a sus originales y comprender sin dificultad el idioma en el que estaban editadas aprovecharon sin duda sus interpretaciones, que reivindicaban de forma más o menos explícita.

En nuestra opinión, la obra que mejor define la constitución académica del Departamento de Geografía en su etapa inicial fue una Miscelánea en Homenaje a Otero Pedrayo en 1978, recordando su breve ejercicio como primer catedrático de Geografía de la institución universitaria compostelana en la década de 1950. Estamos ante un trabajo colectivo, donde participaron buena parte de los profesores e investigadores del recién creado departamento, así como algún autor vinculado directamente con Otero. Entre las contribuciones de la obra, queremos destacar tres -Miralbés (1978); Miralbés, Torres y Pérez Iglesias (1978); y Torres (1978) - por su tratamiento de la montaña y por la relevancia de su autoría. De hecho, la montaña se afirmaba en ese libro determinante como una unidad indiscutible del marco territorial gallego, siempre desde una interpretación de Geografía física, donde se confería una relevancia singular a la disposición del relieve.

Para Miralbés (1978), cabría diferenciar en el relieve gallego las siguientes cuatro unidades: las montañas marginales, la meseta central, las montañas interiores, y la costa y las llanuras litorales. Para esta clasificación hacía referencia a los trabajos geomorfológicos previos de Birot, Solé y Nonn (nunca a García Fernández y su interpretación ruralista). Esta repartición estableció un patrón interpretativo de la organización cuatripartita de la diversidad del relieve gallego que en buena medida perdurará. No obstante, en su discurso sorprenden los calificativos: montañas marginales, se supone que por la lejanía de las sierras del extremo oriental y sudoriental de Galicia, y por la asociación de montaña con margen o borde externo; y montañas interiores, una denominación imprecisa referida a las alineaciones que en sentido meridiano separan a grandes rasgos las provincias de Ourense y Lugo, por un lado, de las de A Coruña y Pontevedra, por el otro. Ninguna de las denominaciones tendrá fortuna (aunque sí el mapa asociado, que en todo caso en el artículo no aparecía publicado), y pasarán a ser sustituidas, respectivamente, por montañas orientales y Dorsal gallega; la denominación de «orientales» apareció ya en una fecha tan temprana como 1979 (Pérez Alberti, 1979). Una segunda anotación curiosa de este trabajo 
nos remite a la búsqueda que Miralbés (1978: 202) hacía de los paralelismos entre el relieve gallego y el español:

[T]odo él [el relieve gallego] está elaborado a partir de la gran superficie de erosión -penillanura fundamental de Galicia- sólo conservada en el interior de la región. Los relieves orientales y meridionales (y los septentrionales y centrales menos destacados) [...] derivaron de aquella superficie de erosión por deformaciones posteriores o son formas residuales. De ahí las analogías de esta penillanura gallega con la Meseta, razón por la que se la denomina frecuentemente meseta central de Galicia. (Miralbés, 1978: 202).

De alguna forma, si el discurso geográfico predominante en España ha consistido en subrayar la importancia de la Meseta para explicar el relieve peninsular (véase, por ejemplo, Dantín Cereceda, 1948, pero la nómina de autores que han ahondado en esta sistemática es enorme), Miralbés intentaba proyectar esta narrativa a Galicia. En otro orden de cosas, desde el punto de vista geológico y geomorfológico esta interpretación es hoy en día dudosa.

Por lo que respecta al trabajo de Torres (1978), esta autora afirmaba al analizar la Galicia meridional que las montañas imponen unos caracteres propios en este espacio. Un poco más adelante, se refería a las sierras y hondonadas del este ourensano (Torres, 1978), sin aludir a su marginalidad, un calificativo que no obstante reaparecía en el artículo conjunto de Miralbés, Torres y Pérez Iglesias (1978) cuando, en la división regional según el mapa de parroquias, volvían a distinguir «las montañas marginales de Galicia». En síntesis, esta primera gran aproximación a la Geografía de Galicia desde la institucionalidad universitaria asociaba montaña a dos grandes sectores del relieve gallego, por lo tanto la convertía en un elemento básico en la definición del marco territorial de la región. Los atributos humanos vinculados a la misma eran su lejanía, su interposición y su marginalidad entre espacios dominados por las penillanuras y los valles.

La interpretación de la montaña como una realidad eminentemente física se mantuvo, aunque desde un enfoque muy diferente y arraigado en la lectura autóctona (galega) del territorio, en el primer (y único) volumen de la Xeografía de Galicia elaborado en esos años desde fuera de la universidad por Pérez Alberti (1982). Utilizando la terminología ya propuesta en Pérez Alberti (1979), este autor denominaba las unidades cuatripartitas de Galicia: el litoral, como aquellas áreas que aparecen entre la costa y las sierras occidentales y septentrionales; las sierras occidentales y septentrionales (las primeras constituyen la Dorsal gallega); las superficies de aplanamiento y las depresiones tectónicas de la Galicia interior; y las sierras orientales y sudorientales. Aunque esta lectura no divergía del esquema general planteado por Miralbés (1978), observamos al menos tres diferencias fundamentales: 
- Desaparecía la interpretación que consideraba hegemónicas las penillanuras en la conformación del relieve gallego (a imitación de la Meseta y de la organización del relieve español) y se optaba por una propuesta en clave gallega.

- Las montañas no eran en ningún caso marginales, sino occidentales, orientales o sudorientales, en base a su localización en el mapa de Galicia.

- Se enriquecía la lectura cuatripartita, de modo que en dos de esas grandes unidades se establecía una diferenciación entre dos grandes conjuntos: las sierras orientales y sudorientales, por un lado, y las sierras occidentales y septentrionales, por el otro.

Además, para Pérez Alberti (1982) la montaña poseía más significados, como en el plano climático, donde se utilizaba para diferenciar un dominio climático propio, el oceánico de montaña, que se diferencia del húmedo, continental o mediterráneo, entre otros. Por último, este autor exponía un argumento, ya presente como hemos visto en Otero Pedrayo (1955: 53), que luego repetirá en distintos trabajos según el cual el concepto de montaña en Galicia es ambivalente en la medida en que la gente considera montaña todo lo que no es valle. Para ello, Pérez Alberti optaba por un criterio que se consolidará a posteriori: los $600 \mathrm{~m}$ de altura.

Entre las múltiples geografías de Galicia que vieron la luz en estos años de transición de finales de los 1970 y principios de los 1980, apenas ninguna merece una mención de interés, salvo una publicada por el colectivo de renovación pedagógica Escola Aberta en 1980. En la misma aparece un último capítulo denominado «A Rexionalización» y firmado por Souto (1980). El análisis realizado estaba directamente influido por las propuestas de ordenación del territorio del país elaboradas en aquella época por el economista Mella (1980) y que defendían la individualización de la montaña oriental gallega como una unidad supracomarcal, donde formular políticas dirigidas a frenar el declive económico y demográfico y a favorecer el desarrollo endógeno (Lois y Aldrey, 2010). En el texto de Souto (1980) se puede observar la influencia de la Geografía física, en particular de Pérez Alberti, pues se produce una especie de correspondencia determinista entre las montañas definidas por la segunda y unos concretos caracteres humanos:

[T]odo lo anterior desencadena una limitada ocupación del suelo, un vacío de población; los pueblos se concentran al pie de la sierra, cerca de los ríos y vías de comunicación, que son escasas, malas y a menudo dejan incomunicados estos pueblos. La vida es ganadera, casi pastoril, con una vegetación autóctona con robles, sauces, castaños... y con escasa explotación forestal. La emigración es muy fuerte, notándose un envejecimiento notable de la población. 
En definitiva, es la Galicia más atrasada y la que vive en peores condiciones. (Souto, 1980: 166).

Como se puede apreciar, estamos ante un compendio de atributos de lo montañés como atraso, ruralidad, pobreza del territorio y despoblación, lógicas que Debarbieux y Rudaz (2010) han rastreado en otros muchos países. En Galicia, se trata de una interpretación muy arraigada y que tenderá a perdurar en el tiempo.

La sistematización de la montaña gallega desde la Geografía se retrasará al menos un decenio más, cuando Torres, Lois y Pérez Alberti (1993) escriban un libro de bolsillo de una colección popular de la Universidade de Santiago de Compostela, que llevará por título A montaña galega: o home e o medio. Estamos ante el trabajo que procura resumir todo el conocimiento sobre estos espacios derivado de los múltiples estudios y monografías previas, que toma las áreas montañosas como el objetivo central y que plantea abiertamente las bases de su delimitación. Este libro se complementó con una preocupación sobre el tema expresada en otros artículos y obras de estos autores, editados en la primera mitad de los años 1990 (entre otros, Torres y Lois, 1995, 1992; Pérez Alberti, Guitián y Ramil, 1993). En un primer repaso por el índice de la obra se aprecian claramente cuáles son las claves interpretativas manejadas por estos geógrafos. Así, parten de una introducción al concepto y los límites de la montaña (en la que de inmediato nos detendremos), seguida por un capítulo sobre los medios de montaña en Galicia (un análisis clásico de Geografía física sobre el tema), la calificación de estos territorios como de «población escasa y rural» (siguiente capítulo), donde se desenvuelve una economía fundamentalmente agraria (con un epígrafe propio) y se puede plantear un análisis sobre «aspectos de Geografía social» (sección final).

En los primeros párrafos de la introducción, los tres autores hacían suyas, y actualizaban, las explicaciones previas de Pérez Alberti (1982) u Otero Pedrayo (1955) cuando se referían a que en Galicia se considera popularmente montaña aquello que no es valle ni llanura. Pero rápidamente se huía de esta concesión subjetivista: «está claro que el geógrafo también debe recurrir a indicadores objetivables, que faciliten la comparación con otros espacios, para definir las áreas de montaña en Galicia» (Torres, Lois y Pérez Alberti, 1993: 13). Para ello, proponían una altitud por encima de los $600 \mathrm{~m}$ y una pendiente media del 10\% como indicadores; como excepción, se incluían dentro de la montaña casos (como la Serra da Capelada) en los que las altitudes son mediocres, pero donde existen pendientes con más del $20 \%$ y abundan relieves escarpados. Un segundo elemento a valorar sería el rigor climático, ya que los terrenos elevados son fríos, lluviosos y expuestos a fuertes vientos. Esta dureza térmica y pluviométrica actúa como repulsiva para el asentamiento humano y el desarrollo de los trabajos del campo. Pasando a los caracteres de tipo humano, se indicaba que la montaña se asocia a densidades de población muy bajas. Los territorios 
de montaña suelen presentar problemas de accesibilidad y, por lo tanto, son espacios poco favorables al desarrollo de actividades industriales y de servicios. La caracterización humana se podría resumir en la siguiente cita:

La débil presencia de colectividades humanas vinculadas a las faenas agrícolas es un elemento consustancial a la definición de montaña. Estas comarcas en el caso de Galicia vienen a reflejar, mejor que ningún otro espacio, los problemas de despoblación y envejecimiento demográfico de todo el interior rural. Asimismo, si consideramos las condiciones climáticas y de altitud de estos sectores no sorprenderá que dentro de las actividades campesinas predominen claramente las orientaciones pecuarias. Las bajas temperaturas invernales imposibilitan el desarrollo de muchos cultivos, por lo tanto las superficies herbáceas y de matorral constituyen lo fundamental en el paisaje. (Torres, Lois y Pérez Alberti, 1993: 16).

Los autores ofrecieron por vez primera una delimitación precisa de la montaña en Galicia, que se acompañaba de una transparencia de los municipios considerados de montaña y que se podía superponer en los distintos mapas temáticos. Partiendo de que en Galicia existía ya entonces, y como hemos ido viendo, cierto acuerdo para denominar como montaña a dos grandes regiones conformadas por multitud de sierras, se proponía distinguir entre: por un lado, todo el este y sureste, es decir, el área de las cadenas montañosas que sirven de límite con Asturias y Castilla y León; por otro, la Dorsal galega, un área alargada de norte a sur, que separaría a grandes rasgos las provincias occidentales de las orientales, y sus hermanas las sierras septentrionales. En relación a los municipios, cabe decir que los autores reconocían la existencia de una delimitación previa de los municipios de montaña efectuada a partir de la legislación correspondiente, ${ }^{6}$ y que abarcaba unos 110 concellos gallegos. Pero en la obra citada propusieron reducirlos a 84 según los criterios marcados por la Geografía. Entre los municipios excluidos de la primera catalogación se destacan los del sur de Lugo, Valdeorras, el eje Arzúa-Melide, A Limia o la ribera fronteriza del Miño, pues su localización en sectores de valle o llanura es indiscutible, y su asimilación a la montaña sólo se explicaba por su carácter de espacios rurales con problemas de despoblación y atonía económica. Entre los municipios incluidos en el mapa aportado, se indicaba que algunos poseen parte de sus parroquias extendidas por áreas llanas o de valle, pero que la imposibilidad de desagregar sus datos estadísticos a escala de detalle obligaba a considerarlos de montaña, aunque mantuvieran pequeños y pujantes núcleos urbanos (como es el caso de Chantada, A Cañiza y, a otro nivel, Monfero).

Las políticas de desarrollo rural y endógeno en la Comunidad Autónoma acabaron apostando a lo largo de los años 1990 y 2000 por los territorios

6. En lo fundamental, la Ley 25/1982, de 30 de junio, de agricultura de montaña. 

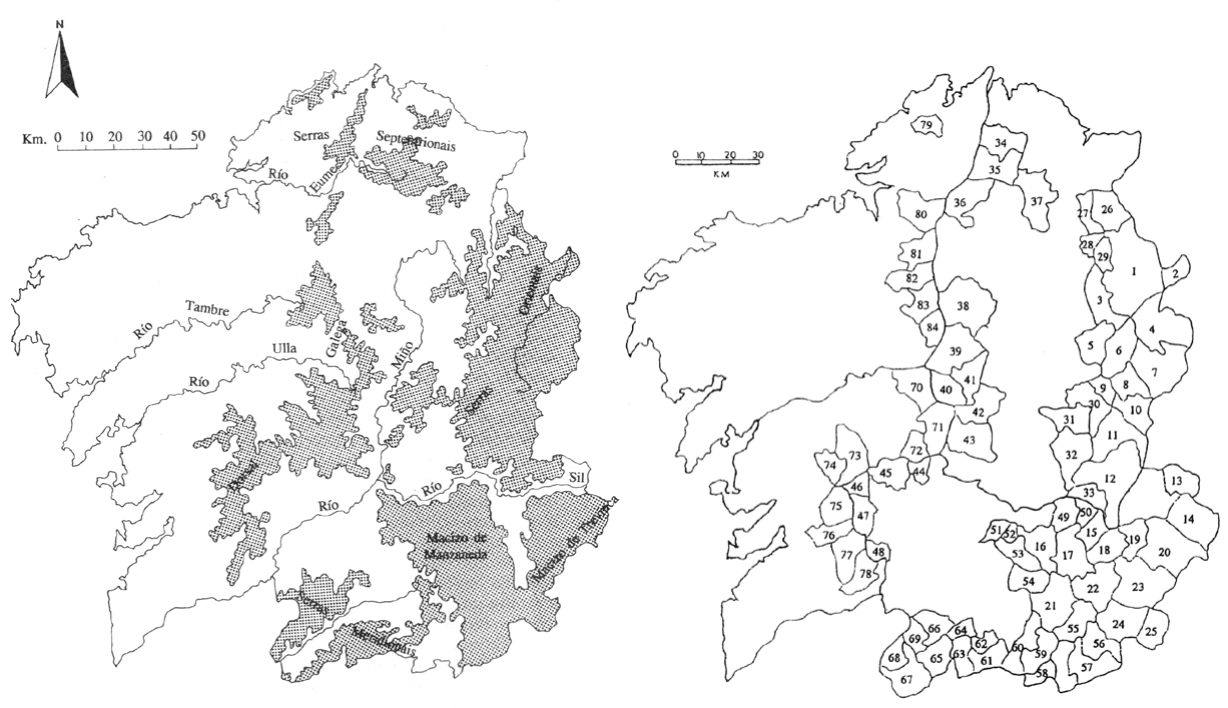

Figura 3. Las montañas y los municipios de montaña de Galicia. Fuente: Torres, Lois y Pérez Alberti (1993: 14, transparencia).

definidos en las estrategias LEADER, PRODER o INTERREG (Paül, 2013; Lois, 2004), de modo que se abandona la posibilidad de un enfoque particular hacia los sectores de montaña individualizados por su altitud, niveles de accesibilidad y variantes climáticas, tal y como Torres, Lois y Pérez Alberti (1993) habían propuesto. A pesar de que la montaña no haya sido considerada un espacio singularizado de intervención en los proyectos de desarrollo financiados por las distintas administraciones en las últimas décadas, su delimitación teórica se ha conservado en la mayoría de las geografías de Galicia, entre ellas las destinadas a la enseñanza secundaria (Lois y Martínez Gargamala, 1998).

Una última precisión sobre este período analizado y las categorías territoriales que generó se refiere a la lectura cultural o geopolítica que se ha venido realizando de la montaña en Galicia, y desde Galicia. De hecho, la propuesta de Pérez Alberti de individualizar los espacios que agrupan alineaciones montañosas según su referencia locacional general (orientales, sudorientales, septentrionales, etc.) ha sido la más difundida. Esto implica el abandono de categorías apreciadas en la Geografía de España, como montañas o macizo galaico-leonés, que en los estudios realizados en Galicia nunca se utilizan y que refuerzan la consideración del territorio gallego como autónomo, unitario y sometido a una interpretación desde dentro, y en función de sus propias lógicas. Así, las sierras orientales y sudorientales separan Galicia de Castilla, con el Bierzo como área de transición, y las sierras meridionales marcan la raia entre 
Ourense y Trás-os-Montes, aun cuando la frontera internacional no siga la línea de cumbres (Trillo-Santamaría y Paül, 2014). Con el resto del Portugal miñoto no existen grandes barreras físicas de demarcación, lo que sería coherente con la lectura territorial del pensamiento galeguista que siempre remarcó la distancia con Castilla, y lo castellano, y la hermandad con lo luso, es decir, con Portugal (González Beramendi y Máiz, 1991).

\section{«ESPACIOS RURALES PERIFÉRICOS EN MUY ACUSADA CRISIS». ${ }^{7}$ LA CONSOLIDACIÓN DEL DIAGNÓSTICO CATASTRÓFICO Y LA AUSENCIA DE POLÍTICAS ESPECÍFICAS}

Los últimos decenios no han incorporado casi ningún discurso novedoso sobre la delimitación y el análisis de la montaña, si bien su lectura como lugar alejado, periférico y con problemas se ha mantenido hasta el presente. Buena prueba de ello son las interpretaciones que desde la Geografía reafirman el carácter litoralizado y urbano de Galicia en la actualidad (Lois y Pino, 2015; Piñeira y Santos, 2011), análisis que se expresa en documentos oficiales de dudosa calidad, pero que reflejan una opinión popular y no reflexiva sobre la montaña en el presente, como la que da título a este epígrafe y que ha sido tomada textualmente de las DOT de la Comunidad Autónoma (Xunta de Galicia, 2011). ${ }^{8}$ Tal vez lo más irónico de esta forma de ver la montaña por parte de las administraciones sea que se trata de una constatación analítica y de diagnóstico muy manida, pero que las propuestas de ordenación al respecto brillan por su ausencia, con «determinaciones» (supuestamente vinculantes según el art. 9 de la Ley 10/1995, de ordenación del territorio de Galicia) que no se pueden más que calificar de peregrinas y dilatorias como la siguiente:

Las Administraciones fomentarán medidas que favorezcan su [de los núcleos rurales con importantes valores patrimoniales] promoción socioeconómica y que permita generar empleo y fijar su población. (Xunta de Galicia, 2011: 304).

7. Las Directrices de Ordenación del Territorio (DOT) de Galicia aprobadas en 2011 indican que «los espacios rurales periféricos», así denominados, «se corresponden con las áreas de montaña», caracterizadas ante todo porque «presentan una muy acusada crisis demográfica» (Xunta de Galicia, 2011: 202).

8. En marzo de 2007 se anunció mediante nota de prensa oficial y artículos periodísticos en las principales cabeceras del país la aprobación de un Plan de Valorización da Montaña Oriental Ourensá, dotado con 10 millones de euros. Preveía unos objetivos amplios y unas medidas genéricas (por ejemplo, la implantación, sin especificar, de senderos o de centros de interpretación), así como la declaración de dos parques naturales: Pena Trevinca y Queixa-San Mamede, este último llamado impropiamente «Macizo Central» - ¿Estará detrás de esta denominación Dantín Cereceda, pues este segundo espacio está culminado por Cabeza de Manzaneda? Sea como fuere, no es correcto considerarlo un «plan» como tal, pues se trataba de un documento esquemático, y en todo caso su efecto real sobre el terreno ha sido nulo, al menos en relación a los parques naturales previstos. 
Sin duda, en épocas recientes la lectura de la montaña como el rural con una crisis más aguda se ha acrecentado y, para demostrarlo, es posible recurrir a distintos ejemplos significativos. Por una parte, las áreas de montaña han sido tomadas como modelo por las distintas administraciones públicas (en especial, la Xunta de Galicia y las Diputaciones) de espacios alejados, abandonados y con serios problemas dotacionales en todos sus análisis y diagnósticos tanto de ordenación del territorio como sectoriales, tal y como las DOT de 2011 evidencian de forma fehaciente. Por otra, esta imagen de aguda crisis se ha trasladado a las políticas medioambientales, como lo demuestra el hecho de que la mayoría de la alta montaña gallega (las sierras orientales y sudorientales) sea catalogada bajo las diferentes figuras de espacio natural protegido vigentes en Galicia (Paül, Santos y Pazos, 2015; Cabalar, 2010). De las 350.000 hectáreas actualmente protegidas en Galicia, 210.000 se corresponden con los «cuatro grandes» espacios protegidos (Os Ancares-O Courel, Pena Trevinca, Queixa-San Mamede y Baixa Limia-O Xurés). Sólo uno de estos espacios (el último) es un parque natural de forma integral (y una pequeña parte de Queixa-San Mamede constituye el Parque Natural do Invernadeiro), mientras que el resto presentan una protección muy vaga (zonas de especial protección de los valores naturales), la de menor categoría que prevé la Ley 9/2001, de conservación de la naturaleza. La Xunta no gestiona ni invierte prácticamente nada en estos espacios, pero en cambio los utiliza cínicamente para sus carteles turísticos promocionales.

Sin lugar a dudas, un primer rasgo que ratifica la aguda crisis de la montaña es la debacle demográfica que sufre. El panorama pesimista reflejado en las obras de los años 1980 y 1990 se ha reafirmado desde entonces. Nos encontramos ante una mayoría de municipios que han perdido por lo general más de la mitad de sus habitantes desde la década de 1960, que contabilizan más de un tercio de la población por encima de los 65 años, porcentajes muy pequeños de población menor de 20 años y una tasa de dependencia del efectivo demográfico elevada, sin que a corto o medio plazos se vislumbre una mejora de esta situación. Por su parte, en términos económicos pocas son las actividades rentables en estos territorios, más allá de una ganadería de calidad (bovina y porcina), asociada a productos con indicación geográfica u otras denominaciones asimilables, la explotación y el cuidado de los recursos forestales, y otras ocupaciones que apenas dan empleo a varias decenas de personas por municipio (recolección de frutos del monte, turismo rural, artesanía, etc.); en todo caso, estas actividades suelen ser esporádicas desde el punto de vista espacial. La industria está ausente de casi todos los territorios y la actividad minera puntual de estas comarcas ha declinado en los últimos decenios. De hecho, dominan las economías locales muy subvencionadas (pensiones de jubilación, servicios financiados desde el exterior, etc.), que ahondan en la imagen de rural en declive y dependiente de 
muchos espacios rurales del interior de Galicia. En Paül $(2015,2013)$ o Lois (2004) aportamos datos concretos que permiten ilustrar esta situación general.

Un segundo elemento que define la imagen de la montaña gallega es el de su perifericidad; estamos frente a comarcas remotas. Este hecho se refuerza por la constatación de que desde Vigo o A Coruña, y en general todo el eje urbano atlántico, es preciso recorrer más de 120,130 o $150 \mathrm{~km}$ para alcanzar las sierras orientales o sudorientales, siempre más de hora y media de desplazamiento por autovías y carreteras. La noción de distancia se acompaña de una percepción de las áreas elevadas como espacios naturales, rurales escasamente modificados por la acción humana (aunque esto no sea habitualmente así). Como consecuencia, se ha registrado una amplia declaración de estas comarcas como espacios protegidos, según sus diferentes figuras, en un proceso que tan solo implica su consideración como territorios poco útiles, consagrados a la protección de sus ecosistemas y a la contemplación, ya que los planes de ordenación de los mismos han sido excepcionales tras su demarcación (Paül, Santos y Pazos, 2015; Cabalar, 2010). La montaña se convierte en el rural lejano, sin capacidad de generar dinámicas de desarrollo endógeno, asociado al problema de los incendios forestales y que es frecuentado por urbanitas ávidos de paisaje, descanso y naturaleza los fines de semana o en vacaciones. Esta lectura reduccionista, pero implícita en los discursos públicos y arraigada socialmente, es una nueva forma de marginalización de la montaña en el presente, incluyendo valores supuestamente conservacionistas, ecológicos y amantes de lo natural, que condena a estas comarcas a una posición pasiva y subordinada a los deseos del mundo urbano en sus estrategias de ordenación territorial (Paül, 2015). El atraso, la pobreza y la inmutabilidad del agro se han sustituido aquí por una visión de la montaña como un territorio que recibe, que es poco capaz de generar novedades o impulsos de cara al futuro.

De todos modos, no siempre la ordenación del territorio como política pública se ha limitado a enumerar los problemas existentes en las áreas de montaña, sin proponer soluciones concretas. Existen dos precedentes ordenadores de la década de 1970 que se convirtieron en meras publicaciones, pero que de hecho pretendían incidir en la realidad territorial gallega, aunque por circunstancias ajenas a los equipos redactores se quedaron tan solo en el papel impreso. Se trata en ambos casos de planes de ordenación realizados desde la Administración General del Estado, en la época de la transición entre la dictadura y la democracia, y que, al producirse las transferencias autonómicas, no fueron considerados para su aprobación e implantación por la Xunta de Galicia. Se produce, por lo tanto, la paradoja de que desde Madrid se llegó en su día a concretar en documentos de planificación bastante más qué hacer con y en la montaña gallega que lo que ha llegado a reflejar por escrito a posteriori el gobierno gallego, supuestamente más próximo a la realidad territorial que vive 
diariamente la ciudadanía por la lógica de la subsidariedad. De todos modos, tampoco nunca llegaremos a saber qué habría sucedido con los planes en cuestión en el caso de que se hubieran tramitado, en el sentido de que perfectamente podrían haber sido modificados en el proceso burocrático-administrativo $\mathrm{y}$, desde luego, la implantación efectiva bien podría haber quedado a gran distancia de las intenciones originales.

El primero de los planes que actúan como precedentes de ordenación es el Plan Director Territorial de Coordinación de Galicia, ultimado como borrador en 1979, al que ya nos hemos referido en Paül, Santos y Pazos (2015) y Lois y Aldrey (2010). Se trataba de un tipo de plan a escala regional, es decir, realizado para el conjunto de Galicia, que estaba posibilitado por la Ley 19/1975, de reforma de la Ley del suelo, que debía establecer «las directrices para la ordenación del territorio, el marco físico en que han de desarrollarse las previsiones del Plan y el modelo territorial en que han de coordinarse los Planes y Normas a que afecte». Existen una serie de concreciones que el borrador de plan introducía, pero la que interesa más a nuestros efectos es la previsión concreta de un sistema de espacios protegidos en Galicia llamados de forma bienintencionada a lo siguiente:

Se trata de defender a una práctica tradicional y racional del aprovechamiento de los recursos naturales de las agresiones motivadas por el proceso de industrialización y urbanización, [...] fuera de actitudes sentimentales y bucólicas, aplicando criterios de rentabilidad y oportunidad a procesos ecológicos y tratando de compatibilizar, mediante una adecuada política de ordenación, las distintas actividades. (MOPU. Centro de Estudios de Ordenación del Territorio y Medio Ambiente, 1979: 113).

Por lo tanto, los espacios naturales protegidos no se diseñaban solo a efectos conservacionistas, sino como herramientas de desarrollo, a imitación posiblemente del modelo ya ensayado en Francia desde finales de la década de 1960 de parcs naturels régionaux. Tenían, así pues, un modelo de gestión asociado que contrasta con la actual desidia institucional al respecto que hemos comentado más arriba. Es muy relevante subrayar que esos espacios naturales protegidos, sobre todo los parques naturales, se diseñaban de manera preferente para las áreas de montaña, especialmente en las sierras orientales y sudorientales, para las que se proponían hasta seis parques naturales, de Norte a Sur: Os Ancares, O Courel, Pena Trevinca, Queixa-San Mamede, Xurés y Castro Laboreiro. Es altamente revelador constatar que, 36 años después, únicamente uno de ellos (y un pequeño sector de otro) haya alcanzado dicho estatus.

El otro documento ordenador de la época que merece nuestra atención se trata de un borrador de plan especial para un área de montaña, para Queixa y San Mamede, que ya analizamos en Paül (2009). Constituye el único plan de ordenación territorial del que tenemos conocimiento realizado en Galicia a 
escala subregional para un sector de montaña. Este plan especial se engarzaba con el Plan Director Territorial:

[E]s a raíz de la puesta en marcha del Plan Director Territorial de Coordinación de Galicia cuando adquiere nuevo impulso el estudio de determinadas zonas, con detectados valores naturales y por lo general de bajo nivel socioeconómico. (MOPU. Centro de Estudios de Ordenación del Territorio y Medio Ambiente, 1981: 22).

A partir de un clásico esquema de análisis, diagnosis y prognosis, el plan especial concretaba un catálogo de acciones coherente que ha permanecido inédito para esa zona como ordenación de conjunto:

- Propuestas sociales, con indicación precisa de infraestructuras de transporte, equipamientos educativos y sanitarios, abastecimiento, saneamiento, etc.

- Propuestas medioambientales, con definición de áreas protegidas (tres niveles de protección) y normas de gestión, incluidas medidas compensatorias a los propietarios.

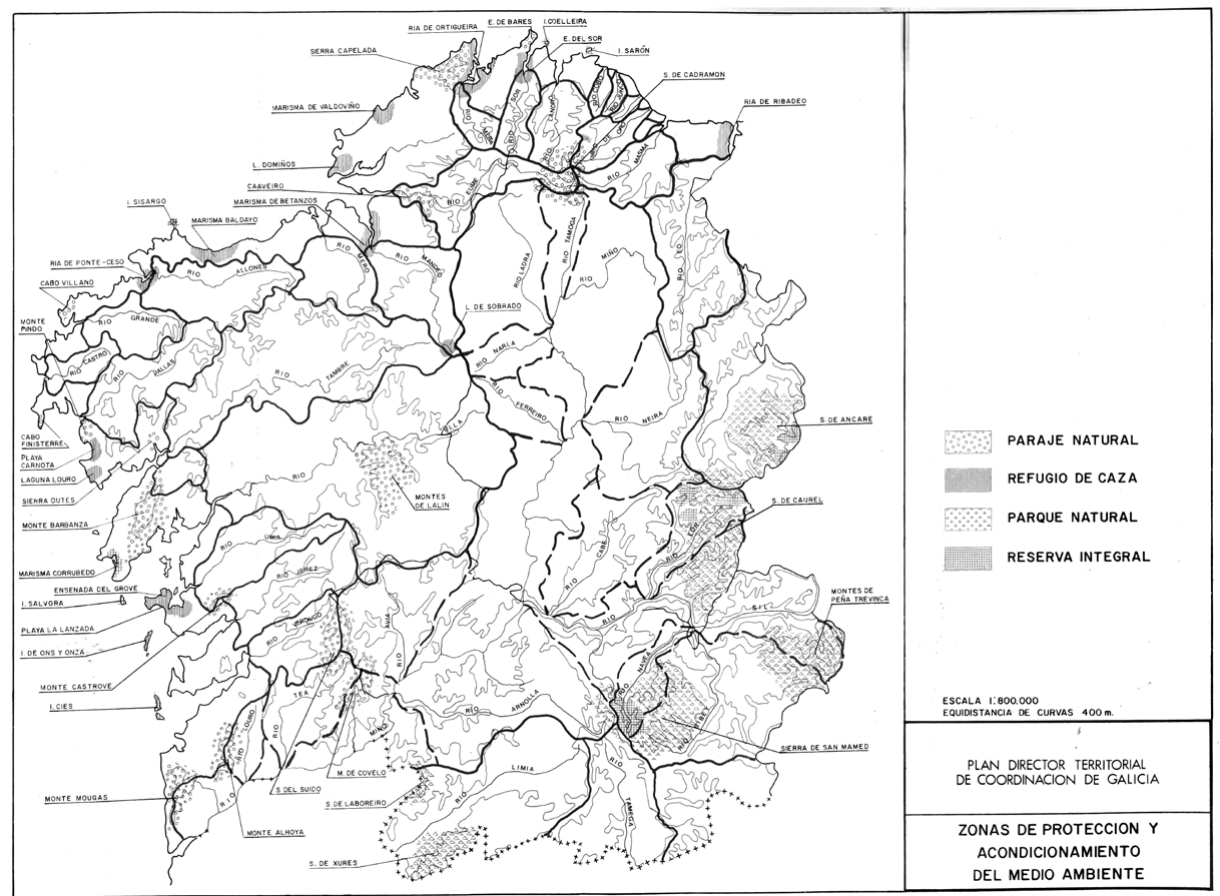

Figura 4. Propuesta de espacios naturales protegidos para Galicia de 1979. Fuente: MOPU. Centro de Estudios de Ordenación del Territorio y Medio Ambiente (1979: s.p.). 


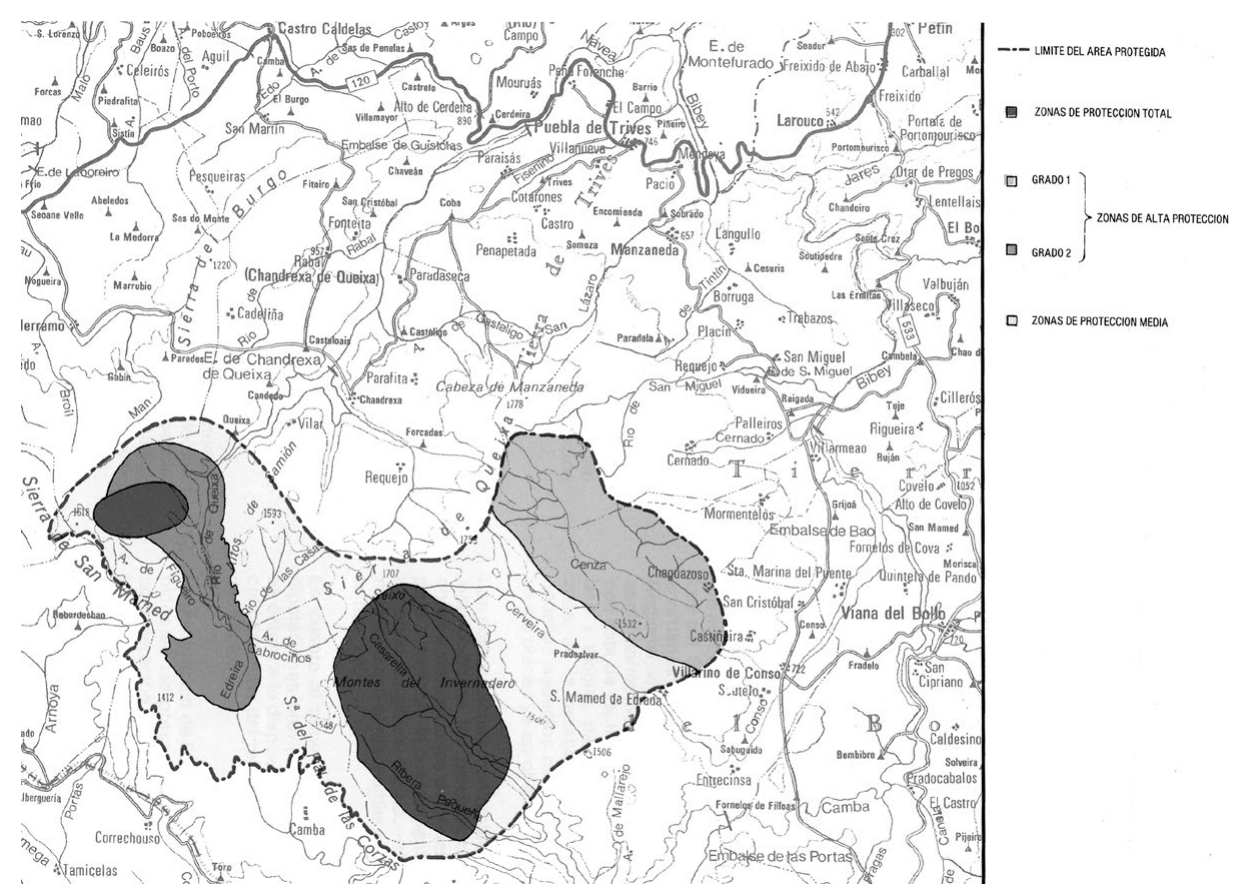

Figura 5. Zonificación de espacios protegidos dentro de la propuesta de parque natural de Queixa-San Mamede. Fuente: MOPU. Centro de Estudios de Ordenación del Territorio y Medio Ambiente (1981: s.p.).

- Propuestas para el desarrollo socioeconómco, afectando a los tres sectores económicos y con especial énfasis en las actividades turísticas: recreativas, deportivas, centros turísticos, etc.

Desde el punto de vista de la Geografía, la atención singularizada por la montaña gallega ha sido limitada; se ha reducido a una serie de trabajos publicados con regularidad, pero poco numerosos. Aunque en la aproximación geomorfológica se ha mantenido el interés por las tierras elevadas, los procesos de modelado glaciar y periglaciar y algunos aspectos de su paisaje (por ejemplo, Carrera y Valcárcel, 2011 o Valcárcel y Pérez Alberti, 2002), se trata más de estudios de caso especializados que de auténticas sistematizaciones de la montaña, ausentes en el discurso al mismo tiempo que las amplias geografías de Galicia por tomos desaparecían de la oferta editorial. En un plano diferente, cabe destacar el trabajo sistemático de los hermanos Guitián (uno biólogo y otro geógrafo) sobre $\mathrm{O}$ Courel y otras sierras orientales de Galicia, desde una dupla perspectiva botánica y biogeográfica, que se complementan a la perfección (Guitián, Guitián y Martínez Villar, 2008). En concreto, estos investigadores de la Universidade de Santiago de Compostela han impulsado la creación de una estación científica de 
esta sierra oriental, donde se vienen realizando actividades académicas de forma continua, como laboratorio del conocimiento biológico, territorial, paisajístico e histórico de la montaña. En otro orden de cosas, la atención por estos espacios se mantuvo entre los años 1990 y mediados de los 2000, cuando en la Licenciatura de Geografía de la Universidad de Santiago de Compostela se ofertó una asignatura optativa consagrada a las áreas de montaña que desapareció con el tránsito al Grado de Geografía y Ordenación del Territorio, y la consiguiente reducción del número de créditos formativos ofertados.

El único autor que ha manifestado una atención investigadora prioritaria por los espacios de montaña en Galicia en épocas recientes ha sido José M. ${ }^{a}$ San Román, formado como Doctor en Santiago de Compostela y docente asociado a la Universidad de León en su Campus de Ponferrada. Este geógrafo comenzó centrando sus investigaciones en la industria extractiva y transformadora de la pizarra de Valdeorras y sus rebordes montañosos (sierras sudorientales), desde una perspectiva de análisis de corte económico y regional al mismo tiempo. Su primera contribución fue una Memoria de Licenciatura, centrada en los municipios de O Barco, Carballeda y Rubiá, y publicada en su mayor parte como San Román (2000). De su original trabajo de investigación faltan los aspectos referidos al impacto ambiental de las canteras de pizarra, que han salido fragmentariamente en otras monografías, debido a las limitaciones que han debido sufrir sus ediciones en el Instituto de Estudos Valdeorreses (una institución encomiable en su labor científica comarcal, pero muy influida por los empresarios y comercializadores de piedra locales). A partir de la citada obra, su tesis evolucionó hacia un estudio integral de los territorios de montaña del límite entre Galicia y Castilla y León (en sus comarcas del Bierzo, La Cabrera y Sanabria), siguiendo los pasos de otros estudios comarcales sobre la montaña realizadas en años anteriores (Cabero, 1976). El amplio trabajo sobre estos espacios se presentó en 2005, obteniendo un importante reconocimiento académico (San Román, 2005). Se trata de un estudio integral de la alta montaña, donde se corrobora la imagen de estos espacios como rurales con agudos problemas de abandono y atonía económica, si bien la actividad minera o ciertas iniciativas empresariales se presentaban como una esperanza relativa en un panorama definido por el declive de la actividad y la dependencia respecto a las ayudas externas.

A mediados del decenio precedente, también cabe anotar la presencia de un geógrafo gallego en los trabajos del colectivo CIMA(Colectivo de Investigadores sobre las Montañas Españolas), que dejó algunos trabajos teóricos de interés sobre el tema (CIMA, 2005a, 2005b). En los mismos se trata de realizar una ordenación de materiales relevantes para el estudio de la montaña y de articular un pequeño vocabulario de términos espaciales referidos a esta cuestión. La propuesta aglutinaba a una decena de profesionales de toda España, donde la impronta de los sectores elevados de las regiones atlánticas fue evidenciada. 
Con respecto a ulteriores estudios de algunos de estos autores sobre el tema de la montaña, ya se constató la desaparición de la presencia gallega en este esfuerzo colectivo.

Por último, los años recientes han significado un nuevo desinterés por las áreas de montaña gallega en los análisis académicos realizados. Una tendencia que quizás, y a falta de una prospección dentro de algún tiempo, parece estar corrigiéndose en la actualidad. De hecho, trabajos en proceso sobre Pena Trevinca o la Baixa Limia reavivan la atención por esta categoría geográfica que, desde 2005, sólo ha merecido una reflexión limitada (salvando el caso ya citado de O Courel) en algunos pocos artículos publicados en revistas españolas de prestigio. Lois, San Román y Aldrey (2008) volvieron a reflexionar sobre el impacto de la actividad minera en la montaña galaico-leonesa, comparando la pizarra de Valdeorras y La Cabrera con el carbón del Bierzo. Resulta curioso que, por primera vez, los tres geógrafos de formación compostelana utilicen la expresión «galaico-leonesa» para referirse a los sectores elevados, una expresión tan poco empleada en la Comunidad Autónoma de origen. En todo caso, la comparación con el Bierzo y el hecho de que la contribución se inserte en un número especialmente dedicado a la montaña en toda España y derivado de los análisis del grupo CIMA, explican esta situación. Los mismos autores (Aldrey, Lois y San Román, 2008) volvieron a plantear la cuestión de la dinámica territorial y sociodemográfica, en este caso de la montaña gallega, en un segundo trabajo también perteneciente a un volumen especial consagrado al tema. A su vez, Paül (2009) realizó un análisis de la ordenación del territorio y del turismo en el Parque Natural do Invernadeiro, en el que resaltó las contradicciones existentes en el modelo mantenido por inercia en la gestión de dicha área protegida desde principios de la década de $1990 \mathrm{y}$, en este sentido, la necesidad de plantear un salto de escala y englobar al conjunto de las sierras de Queixa y San Mamede a efectos de un desarrollo local y una planificación territorial más coherentes. Como derivada de esta investigación, Paül (2011) ofreció una lectura paisajística de este mismo ámbito de estudio de las sierras sudorientales de Galicia.

\section{A MODO DE CONCLUSIONES}

Vilà Valentí (1991) exponía cómo se fue conformando a lo largo de los siglos una visión tripartita del relieve catalán, modelo que ha tenido fortuna y en la actualidad está aceptado y difundido. No compartimos con este autor la idea de que esta repartición haya tenido éxito porque se asemeje a la realidad entendida como verdad -el enfoque aquí adoptado nos hace dudar de que las representaciones deban ser «realistas» para triunfar. Sin embargo, nos interesa tomar de él la importancia fundamental de la variable evolutiva en la creación de modelos organizativos de las montañas de un territorio dado, perspectiva coherente con 
el enfoque constructivista. En este sentido, creemos haber demostrado cómo la visión del relieve gallego se movió bajo la sombra del desconocimiento directo y del caos durante siglos, desde los primeros mapas del seiscientos. Hasta tal punto la imagen desorganizada de las montañas gallegas campaba que el propio padre simbólico de la Geografía gallega no atinó centurias después a ofrecer un modelo convincente de explicación de las «formas complicadas» a mediados del siglo xx; ello a pesar de la propuesta coetánea de Dantín Cereceda, que en el caso que nos ocupa no parece ser demasiado adecuada. En todo caso, cabe subrayar que desde los mapas del siglo XVII encontramos una constante que se mantiene hasta la actualidad: la idea de que por oriente Galicia está separada de las actuales Castilla León y Asturias por relieves de entidad, asunción que, como hemos venido insistiendo, cabe entender como una construcción heredada del pasado, asociada a toda una plétora de imágenes persistentes de baja accesibilidad, puertos de montaña cerrados algunos días en invierno, dificultades de comunicación, coste de las infraestructuras de transporte e incluso marginalidad espacial.

Fue la Geografía institucionalizada en las décadas de 1970 y 1980 la que concluyó al fin que «pueden distinguirse las grandes unidades del relieve gallego», no sin titubeos sobre todo en lo que se refiere a las denominaciones a emplear. La obra que culminó esta construcción académica es sin duda Torres, Lois y Pérez Alberti (1993). La organización cuatripartita resultante identifica dos conjuntos montañosos principales: la Dorsal galega y las sierras septentrionales, por una parte; y las sierras orientales y sudorientales, por otra. Tal y como hemos defendido, este modelo resultante atiende a una lectura cultural o geopolítica en clave gallega. Hemos explicado cómo en la actualidad se acepta comúnmente esta repartición, por ejemplo por parte de la investigación desarrollada a posteriori, que también hemos tenido ocasión de analizar.

Sin embargo, y a diferencia de lo sucedido en otros contextos presentados en el primer apartado, no se puede afirmar que la presencia de un marco de referencia compartido sobre el relieve gallego haya supuesto su puesta en valor ni su toma en consideración en términos de ordenación del territorio, protección de ámbitos concretos, consciencia social o desarrollo turístico efectivo. En particular, nos parece muy revelador que no se hayan elaborado planes específicos de desarrollo de las zonas de montaña, más allá de unos antecedentes remotos de hace casi cuatro décadas, y que las recientes DOT aprobadas en 2011 asistan en la práctica impotentes a la «muy acusada crisis» que ellas mismas se encargan de analizar.

El motivo por el que las montañas gallegas siguen siendo un ámbito rezagado para las administraciones públicas, y para la sociedad de Galicia, es difícil de dilucidar. Sin embargo, y siguiendo la estela teórico-conceptual por la que hemos transitado a lo largo de esta contribución, pensamos que de algún modo 
actúa con fuerza el imaginario cultural nacional derivado de Rosalía de Castro, y desarrollado en buena medida por Otero Pedrayo (Paül y Labraña, 2013; López Sández, 2008). Este imaginario ha concentrado la mirada en los espacios agrarios y rurales productivos de la Galicia media, que reúnen en buena medida el potencial simbólico del país, y que se ha concretado, por ejemplo, en la creación de una Consellaría do Medio Rural en 2005 muy centrada en la agricultura, que, a pesar de los cambios constantes en el portafolio gubernamental, ha subsistido hasta fecha de hoy, una década después. En cambio, este imaginario cultural gallego ha omitido, o al menos tratado en segundo plano, la montaña. La persistencia de estas representaciones nos parece relevante para explicar en buena medida que la «invención» de las montañas, por utilizar la expresión de Frolova (2006), sea tímida, por no decir que ausente, en el caso gallego.

Por otro lado, no se puede obviar que buena parte de los discursos que más han tendido a utilizar las montañas en sus imaginarios paisajísticos son nacionalistas. Si bien los nacionalismos con potentes imaginarios montañeros han alcanzado el poder por períodos dilatados en naciones sin estado (caso de Catalunya o el País Vasco dentro de España) o son parte constitutiva e inmanente de los estados-nación a modo de nacionalismos banales así denominados por Billig (1995) (Suiza, Francia, España en su conjunto), es evidente que en Galicia la extensión de un nacionalismo gallego con su ideología paisajística asociada ha sido limitada; a ello también se puede deber el escaso aprecio colectivo por las montañas gallegas. Sin el cinismo gongoriano, «al fin, gallegos y montes, / nadie dirá que os ofendo».

\section{REFERENCIAS}

Aldrey, J.A.; Lois, R.C. y SAn Román, J.M.a (2008): «Dinámica territorial y sociodemográfica de la montaña gallega», Poligonos. Revista de Geografía, 18: 13-36.

BeIRas, X.M. (1972): O atraso económico de Galicia. Vigo: Galaxia.

Bertrand, J.R. (1992): A poboación de Galicia. Estudios xeográficos. Santiago de Compostela: Universidade de Santiago de Compostela.

BilLig, M. (1995): Banal Nationalism. London: SAGE.

Birot, P. y SolÉ, L. (1953): Recherches morphologiques sur le NO de la Péninsule Ibérique. Paris: Centre National de la Recherche Scientifique.

BouHIER, A. (1979): La Galice. Essai d'interprétation d'un vieux complexe agraire. La Roche-sur-Yon: Imp. Yonnaise.

BouZA, F. (2009): «Dar Galicia y el gallego a la imprenta. As galegadas y A História de Galicia de Lobariñas Feijoo, la Verdadera Descripción de Ojea y algunas iniciativas historiográficas de la primera mitad del siglo xvII». Obradoiro Historia Moderna, 18: 9-44.

Cabalar, M. (2010): O uso público nos Espazos Naturais Protexidos de Galicia. Diagnose e propostas de actuacións. Santiago de Compostela: Universidade de Santiago de Compostela. [Tesis doctoral inédita] 
CABero, V. (1976): Estudio geográfico de un espacio marginal en las montañas galaico-leonesas: La Cabrera. Salamanca: Universidad de Salamanca. [Tesis doctoral inédita]

CARrera, P. y VAlCÁRCEL, M. (2011): «La cubierta nival y su acción geomorfológica en el Pico Cuíña, Sierra de Ancares (NO de la Península Ibérica)», en Valcárcel, M. y Carrera, P. (eds.): Criosferas, suelos congelados y cambio climático. Lugo: Deputación de Lugo / Universidade de Santiago de Compostela. pp. 169-203.

Castelao, D.A.R. (1944): Sempre en Galiza. Buenos Aires: Centro Orensano de Buenos Aires. [Ed. (1994). Madrid: Akal]

CIMA (2005a): Las montañas españolas: conceptos y vocabulario. Madrid: Entinema.

CIMA (2005b): Las montañas españolas. Territorio, sociedad, patrimonio y cultura. Materiales para el conocimiento y la difusión de los espacios de montaña. Salamanca: Dolmen Multimedia.

Dantín Cereceda, J. (1948): Resumen fisiográfico de la Península Ibérica. Madrid: Consejo Superior de Investigaciones Científicas.

Debarbieux, B. (2004): «The symbolic order of objects and the frame of geographical action: An analysis of the modes and effects of categorisation of the geographical world as applied to the mountains in the West», GeoJournal, 60: 397-405.

Debarbieux, B. y Rudaz, G. (2010): Les faiseurs de montagne. Paris: Centre National de la Recherche Scientifique.

Frolova, M. (2006): Les Paysages du Caucase. Invention d'une montagne. Paris: Éditions du Centre des Travaux Historiques et Scientifiques.

García Álvarez, J. (2013): «Paisaje, memoria histórica e identidad nacional en los inicios de la política de conservación de la naturaleza en España: de Covadonga a San Juan de la Peña», Hispania: Revista española de historia, 73(244): 409-438.

GARCÍA FERnÁNDEZ, J. (1975): Organización del espacio y economía rural en la España Atlántica. Madrid: Siglo XXI.

GonzÁlez BERAMENDI, J. y MÁIz, R. (comps.) (1991): Los nacionalismos en la España de la II. ${ }^{a}$ República. Madrid: Siglo XXI.

Guitián, J.; Guitián, L. y Martínez Villar, J.L. (2008): Guía do Courel. Vigo: Xerais.

Huetz De Lemps, A. (1967): Vignobles et vins du nord-ouest de l'Espagne. Bordeaux: Institut de Géographie.

Humbdolt, A. von (1828): Tableaux de la nature. [Traducción al español: Humbdolt, A. von (2003): Cuadros de la Naturaleza. Madrid: Los Libros de la Catarata]

LoIs, R.C. (2004): «Estrutura territorial de Galicia», en: Rodríguez González, R. (dir.): Os concellos galegos para o século XXI. Análise dunha reestruturación do territorio e do goberno local. Santiago de Compostela: IDEGA / FEGAMP. vol. I, pp. 101-160.

LoIs, R.C. y AldREy, J.A. (2010): «El problemático recorrido de la ordenación del territorio en Galicia», Cuadernos Geográficos, 47(2): 583-611.

Lois, R.C. y Martínez Gargamala, H. (1998): Xeografía de Galicia. Madrid: Obradoiro-Santillana.

Lois, R.C. y Pino, D. del (eds.) (2015): A Galicia urbana. Vigo: Xerais. 


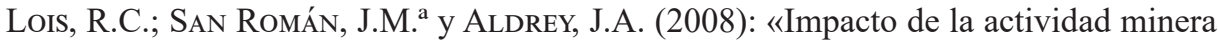
en la población de los espacios de montaña. La pizarra y el carbón en las montañas galaico-leonesas», Ería. Revista cuatrimestral de geografía, 75: 99-113.

LóPEz SÁNDEZ, M. (2008): Paisaxe e nación. A creación discursiva do territorio. Vigo: Galaxia.

Lorenzo, R. y SÁEz, A. (dirs.) (1989): Cartografía de Galicia 1522-1900. Madrid: Instituto Geográfico Nacional / Instituto de Cooperación Iberoamericana.

MARTíneZ DE PIsón, E. (2004): «El paisaje de montaña. La formación de un canon natural del paisajismo moderno», en Ortega Cantero, N. (ed.): Naturaleza y cultura del paisaje. Soria / Madrid: Fundación Duques de Soria / Universidad Autónoma de Madrid. pp. 53-121.

Mella, X.M. (1980): «Fundamentos teóricos para un ensaio da comarcalización de Galicia», Revista Galega de Estudios Agrarios, 3: 85-110.

MÉndez Martínez, G. (2001): «El territorio en imágenes. Cartografía histórica», en Precedo, A. y Sancho, J. (dirs.); Villarino, C. (coord.): Atlas de Galicia. Tomo I: Medio Natural. Santiago de Compostela: Sociedade para o Desenvolvemento Comarcal de Galicia. pp. 22-39.

MÉndez Martínez, G. (com.) (2005): Cartografía de Galicia [sS. XVI ó XIX]. Colección Puertas-Mosquera. Santiago de Compostela: Universidade de Santiago de Compostela.

MiralbÉs, R. (1978): «Caracterización geográfica de Galicia», en Miscelánea de Geografia de Galicia en Homenaje a Otero Pedrayo. Santiago de Compostela: Universidad de Santiago de Compostela. pp. 193-253.

Miralbés, R.; Torres, M. ${ }^{a}$ P. de y PÉrez Iglesias, M. ${ }^{a} L$. (1978): «El mapa de parroquias rurales de Galicia y sus aldeas», en Miscelánea de Geografía de Galicia en Homenaje a Otero Pedrayo. Santiago de Compostela: Universidad de Santiago de Compostela. pp. 411-425.

MOpu. Centro de Estudios de Ordenación del Territorio y Medio Ambiente (1979): Plan Director Territorial de Coordinación de Galicia. Propuesta de Objetivos y Estrategias para Galicia. Santiago de Compostela: Xunta de Galicia.

MOPU. Centro de Estudios de Ordenación del Territorio y Medio Ambiente (1981): Sintesis del Plan Especial de San Mamed y Sierra de Queixa. Madrid: Ministerio de Obras Públicas y Urbanismo-Centro de Estudios de Ordenación del Territorio y Medio Ambiente.

Mounier, J. (1979): Les climats océaniques des régions atlantiques de l'Espagne et du Portugal. Lille: Université de Rennes II.

Murado, M.-A. (2008): Otra idea de Galicia. Barcelona: Debate.

NoguÉ, J. (2005): «Nacionalismo, territorio y paisaje en Cataluña», en Ortega Cantero, N. (ed.): Paisaje, memoria histórica e identidad nacional. Soria/ Madrid: Fundación Duques de Soria / Universidad Autónoma de Madrid. pp. 147-169.

Nonn, H. (1969): Les régions côtières de la Galice (Espagne). Paris: Ophrys.

Ortega Cantero, N. (1987): Geografía y cultura. Madrid: Alianza.

Ortega Cantero, N. (1997): «Juan Dantín Cereceda y la Geografía española», Ería. Revista cuatrimestral de geografía, 42: 7-34. 
Otero Pedrayo, R. (1926): Síntese xeográfica de Galicia. Santiago de Compostela: Lar.

Otero Pedrayo, R. (1955): «Composiciós e ritmos. Un ensaio de crasificación», en Paisaxe e Cultura. Ensaios. Vigo: Galaxia. pp. 39-57.

PAÜL, V. (2009): «El turismo en el Parque Natural do Invernadeiro. Situación heredada y perspectivas de cambio», Cuadernos de Turismo, 24: 135-167.

PAÜL, V. (2011): «O Invernadeiro: de monte de pinos de repoblación forestal a parque natural», en Molinero, F.; Ojeda, J. F. y Tort, J. (coords.): Los paisajes agrarios de España. Caracterización, evolución y tipificación. Madrid: Ministerio de Medio Ambiente y Medio Rural y Marino. pp. 457-470.

PAÜL, V. (2013): «Hopes for the Countryside’s Future. An Analysis of Two Endogenous Development Experiences in South-Eastern Galicia», Journal of Urban and Regional Analysis, 5(2): 169-192.

PAÜL, V. (2015): «Que espazos rurais nun país urbano? Dúas aproximacións xeográficas ao rural galego», en Lois, R.C. y Pino, D. del (eds.): A Galicia urbana. Vigo: Xerais. pp. 693-714.

PAÜL, V. y LABrañA, S. (2013): «As paisaxes do mar galego. Unha liña interpretativa crítica», Sémata. Ciencias Sociais e Humanidades, 25: 29-62.

PaüL, V.; SAntos, X.M. y PAzos, M. (2015): «The Ambiguous Geographies of Protected Areas in Galicia», Ambiente y Desarrollo. International Journal of Development and Environment, 19(36): 61-77.

Pérez Alberti, A. (1979): Xeografía de Galiza. Proxecto experimental de ciencias sociais de Galiza. Madrid: Santillana.

Pérez Alberti, A. (dir.) (1982): Xeografía de Galicia. Tomo I: O Medio. Sada: Sálvora.

Pérez Alberti, A.; Guitián, L. y Ramil, P. (1993): La evolución del paisaje de las montañas en los entornos del Camino de Santiago. Santiago de Compostela: Xunta de Galicia.

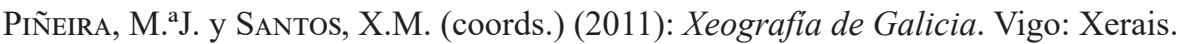

Price, M.F.; Jansky, L. y Iastenia, A.A. (eds.) (2004): Key Issues for Mountain Areas. New York: United Nations University Press.

Roma, F. (2002): El paradís indicible. La representació de Montserrat durant l'edat moderna. Manresa: Centre Excursionista Comarca de Bages.

Roma, F. (2004): Del Paradís a la Nació. La muntanya a Catalunya. Segles XV-XX. Valls: Cossetània.

SaCAReau, I. (2003): La montagne. Une approche géographique. Paris: Belin.

SAN Román, J.M. ${ }^{\text {a }}$ (2000): Valdeorras. La industria de la pizarra y las transformaciones espaciales. Municipios de O Barco, Carballeda y Rubiá (1950-1998). Madrid: Instituto de Estudios Valdeorreses.

SAn Román, J.M.' (2005): Las transformaciones espaciales recientes en las áreas montañosas colindantes entre Ourense y Castilla y León. Un estudio de Geografía Regional. Santiago de Compostela: Universidade de Santiago de Compostela. [Tesis doctoral inédita]

SAn Román, J. Ma . (2012): «Dinámica socioeconómica en La Cabrera y ¿desarrollo territorial basado en la minería?», en Delgado, C. y Plaza, J.I. (eds.): «Territorio y 
Paisaje en las montañas españolas. Estructuras y Dinámicas Espaciales». Estructuras y dinámicas espaciales, pp. 73-83.

Santos, X.M. (1999): «Xeografía e nacionalismo en Galicia», en Professor Vilà Valentí. El seu mestratge en la geografia universitària. Barcelona: Universitat de Barcelona. pp. 1343-1356.

Schulz, G. (1835): Descripción geognóstica del Reino de Galicia, acompañada de un mapa petrográfico de este país. Madrid: Imprenta de los Herederos de Collado. [Ed. facsimilar (1994). Sada: Ediciós do Castro]

Souto, X.M. (1980): «A rexionalización de Galicia», en Escola Aberta: Galicia. A nosa terra. Santiago de Compostela: Escola Aberta. pp. 150-185.

TORRES, M.P. de (1978): "Galicia meridional: aportación a la división comarcal de Galicia», en Miscelánea de Geografía de Galicia en Homenaje a Otero Pedrayo. Santiago de Compostela: Universidad de Santiago de Compostela, pp. 383-411.

Torres, M. ${ }^{a}$ P. de y LoIs, R.C. (1992): «Le rôle des bourgs dans la montagne de Galice», en CERAMAC: Des régions paysannes aux espaces fragiles. Clermont-Ferrand: CERAMAC-Université Blaise Pascal. pp. 207-215.

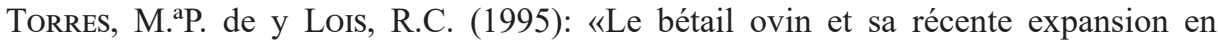
Galice (Espagne)», en CERVIR: Les mutations dans le milieu rural. Caen: Presses Universitaires de Caen, pp. 123-131.

Torres, M. ${ }^{a}$ P. de y LoIs, R.C. (1999): «Lectura geográfica de los espacios rurales y el mundo campesino en Galicia. Estado de la cuestión», en Professor Joan Vilà Valentí. El seu mestratge en la geografia universitària. Barcelona: Universitat de Barcelona. pp. 851-864.

Torres, M.P. de; Lois, R.C. y PÉrez Alberti, A. (1993): A montaña galega. O home e o medio. Santiago de Compostela: Universidade de Santiago de Compostela.

Trillo-Santamaría, J.M. y Paül, V. (2014): «The Oldest Boundary in Europe? A Critical Approach to the Spanish-Portuguese Border: The Raia between Galicia and Portugal», Geopolitics, 19(1): 161-181.

Valcárcel, M. y Pérez Alberti, A. (2002): «La Sierra de los Ancares: itinerario geomorfológico», en Redondo, J.M. ${ }^{a}$ et al. (coords.): XVII Jornadas de Geografía Física. León: Universidad de León. pp. 148-164.

VilÀ VAlEntí, J. (1991): «Les unitats majors del relleu a Catalunya. Història d'uns conceptes», Memorias de la Real Academia de Ciencias y Artes de Barcelona, 887(5): 191-248.

Xunta de Galicia (2011): Directrices de ordenación do territorio. Santiago de Compostela: Xunta de Galicia. 